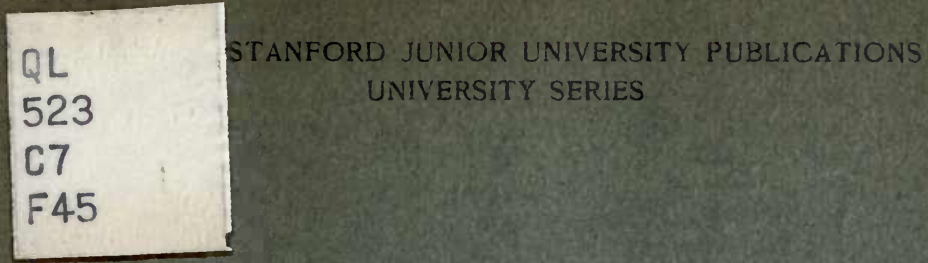

\title{
A CONTRIBUTION TO THE
}

\section{KNOWLEDGE OF THE COCCIDAE}

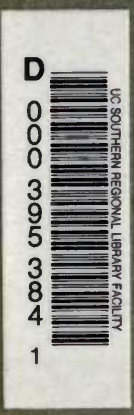

OF

SOUTHWESTERN UNITED STATES

\author{
BY \\ GORDON FLOYD FERRIS \\ Instructor in Entomology
}

STANFORD UNIVERSITY, CALIFORNIA

PUBLISHED BY THE UNIVERSITY

1919 


LELAND STANFORD JUNIOR UNIVERSITY PUBLICATIONS UNIVERSITY SERIES

\section{A CONTRIBUTION TO THE}

\section{KNOWLEDGE OF THE COCCIDAE OF}

\section{SOUTHWESTERN UNITED STATES}

BY

\section{GORDON FLOYD FERRIS} Instructor in Entomology 


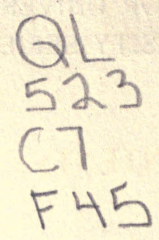

STANFORD UNIVERSITY

Press 


\section{CONTENTS}

Introduction

Systematic treatment . . . . . . . . . 7

Genus Paleococcus . . . . . . . . . . . . . 7

Paleococcus morrilli Ckll. . $\quad . \quad$. $\quad . \quad$. $\quad . \quad$. $\quad .8$

Paleococcus plucheae Ckll. (?) . . . . . . . . . . 10

Paleococcus townsendi Ckll. (?) . . . . . . . . 10

Genus Icerya . . . . . . . . . . . . . . . 11

Icerya rileyi Ckll. $\quad . \quad$. $\quad . \quad$. $\quad . \quad$. $\quad . \quad$. $\quad . \quad 12$

Genus Stomacoccus . $\quad . \quad$. $\quad . \quad$. $\quad . \quad$. . . . . 13

Stomacoccus platani Ferris $\quad . \quad$. $\quad . \quad$. $\quad . \quad . \quad . \quad 13$

Genus Xylococcus . $\quad . \quad$. $\quad . \quad$. $\quad . \quad$. $\quad . \quad$. $\quad .13$

Xylococcus macrocarpae Coleman $\quad . \quad$. $\quad . \quad$. $\quad . \quad$. 13

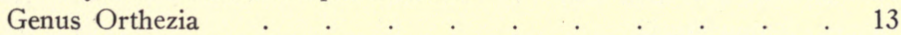

Orthezia nuda n. sp. . . . . . . . . . . . . . 13

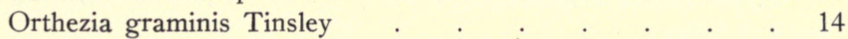

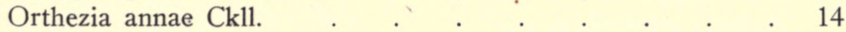

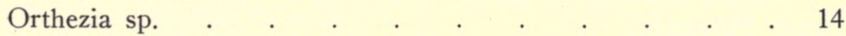

Genus Lecaniodiaspis . $\quad . \quad$. $\quad . \quad$. $\quad . \quad$. . $\quad .14$

Lecaniodiaspis rufescens (Ckll.) (?) . . . . . . . . 14

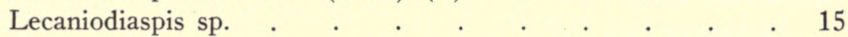

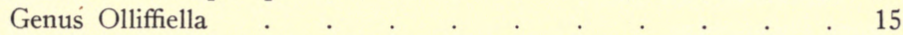

Olliffiella cristicola Ckll. . $\quad . \quad$. $\quad . \quad$. $\quad . \quad$. $\quad . \quad 15$

Genus Eriococcus . . . . . . . . . . . . 17

Eriococcus bahiae Ehrh. . . . . . . . . . 18

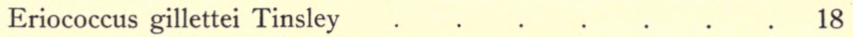

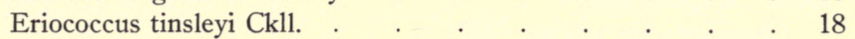

Genus Fonscolombia . . . . . . . . . . 18

Fonscolombia yuccae n. sp. $\quad . \quad$. $\quad . \quad$. $\quad . \quad$. . . 18

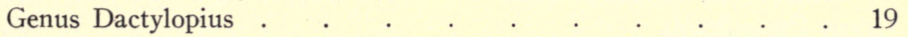

Dactylopius confusus (Ckll.) . . . . . . . . . $\quad$. 20

Dactylopius indicus (Green) . . . . . . . $\quad$. 20

Dactylopius tomentosus (Lam.) . . . . . . 20

Genus Puto . . . . . . . . . . . 20

Puto yuccae (Coq.) . $\quad . \quad$. $\quad . \quad$. $\quad . \quad$. $\quad . \quad$. 20

Genus Phenacoccus . . . . . . . . . . 20

Phenacoccus betheli Ckll. .. . $\quad$. . . . . $\quad$. 20

Phenacoccus helianthi (Ckll.) . $\quad . \quad$. $\quad . \quad$. . . 22 
Genus Heterococcus

Heterococcus arenae Ferris 22

Genus Lachnodius . . . . . . . . . . 23

Lachnodius salicis n. sp. . . . . . . . . . 23

Genus Pseudococcus . . . . . . . . . 24

Pseudococcus ephedrae (Coq.) . . . . . . . . . . $\quad$. 24

Pseudococcus gutierreziae (Ckll.) . . . . . . . . $\quad .26$

Pseudococcus irishi (Ckll.) . . . . . . . . . . 27

Pseudococcus juniperi Ehrh . . . . . . . . 28

Pseudococcus prosopidis (Ckll.) . . . . . . . 29

Pseudococcus lycii n. sp. . $\quad$. $\quad$. $\quad$. . . . $\quad$. 30

Pseudococcus steelii (Ckll.) . . . . . . . . . . 31

Genus Erium . . . . . . . . . . . . . 31

Erium lichtensioides (Ckl1.) . . . . . . . . . . 31

Genus Ripersia $. \quad . \quad . \quad . \quad . \quad . \quad . \quad . \quad . \quad .31$

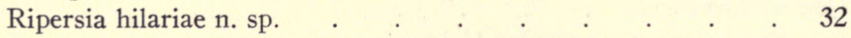

Ripersia sporoboli Ckll. (?) . . . . . . . 33

Genus Cryptoripersia . . . . . . . . . 33

Cryptoripersia arizonensis (Ehrh.) . . . . . . . . 34

Genus Aclerda . $\quad . \quad$. $\quad . \quad$. $\quad . \quad$. $\quad . \quad$. $\quad . \quad$. 34

Aclerda ariditatis n. sp. $\quad . \quad$. $\quad . \quad$. $\quad . \quad . \quad$. $\quad . \quad 34$

Genus Pulvinaria $. \quad . \quad . \quad . \quad . \quad . \quad . \quad . \quad$. $\quad .36$

Pulvinaria bigeloviae Ckll..$\quad$. $\quad . \quad$. $\quad . \quad$. $\quad . \quad 36$

Genus Lichtensia . $\quad . \quad$. $\quad . \quad$. . . . . . 38

Lichtensia lycii Ckll. . $\quad . \quad$. $\quad$. $\quad$. $\quad . \quad$. $\quad . \quad$. $\quad 38$

Genus Philephedra . $\quad . \quad$. $\quad . \quad$. $\quad . \quad$. $\quad . \quad$. $\quad$. 39

Philephedra ephedrae Ckll. $\quad . \quad$. $\quad . \quad$. $\quad . \quad$. $\quad 39$

Genus Ceroplastes . . . . . . . . . . . 41

Ceroplastes irregularis Ckll. . . . . . . . . . 41

Genus Ceroplastodes . . . . . . . . . 43

Ceroplastodes acaciae Ckll. $\quad . \quad$. $\quad . \quad$. $\quad . \quad$. $\quad . \quad$. 43

Genus Toumeyella . . . . . . . . . . . . 44

Toumeyella mirabilis Ckll. . . . . . . . . . 44

Genus Protodiaspis . . . . . . . . . . . 46

Protodiaspis tridentata n. sp. . . . . . . . . . . 46

Protodiaspis edentata n. sp..$\quad$. $\quad . \quad$. . . . . $\quad$. 48

Genus Diaspis . . . . . . . . . . . 49

"Diaspis" arizonica Ckll. . . . . . . . . . . . . . 49

Diaspis montana Ckll..$\quad$. $\quad$. $\quad$. $\quad$. $\quad$. $\quad . \quad 50$

Diaspis toumeyi Ckll. $\quad . \quad$. $\quad . \quad$. $\quad . \quad$. $\quad . \quad$. 51 
Genus Pseudodiaspis

Pseudodiaspis atriplicis n. sp.

Pseudodiaspis condaliae n. sp. . . . . . . . . 54

Pseudodiaspis parkinsoniae (Ckll.) . . . . . . . . 56

Genus Xerophilaspis . . . . . . . . . . $\quad . \quad 57$

Xerophilaspis prosopidis Ckll. . . . . . . . . . 58

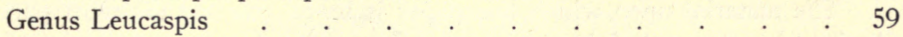

"Leucaspis" cupressi Coleman . . . . . . . . 59

Genus Lepidosaphes . . . . . . . . . . . 60

Lepidosaphes concolor (Ckll.) . . . . . . . . . 60

Lepidosaphes ceanothi n. sp. . . . . . . . . . 62

Genus Aspidiotus . . . . . . . . . . . . 63

Aspidiotus candidulus Ckll. $\quad . \quad$. $\quad . \quad . \quad . \quad . \quad$. $\quad .63$

Aspidiotus covilleae n. sp. . . . . . . . . . . . . 64

Aspidiotus graminellus Ckll. (?) . . . . . . . . . 65

Genus Chrysomphalus . $. \quad . \quad . \quad . \quad . \quad . \quad . \quad .66$

Chrysomphalus covilleae n. sp. . . . . . . . . . . $\quad .66$

Supplement . . . . . . . . . . . . . 68

Phenacoccus betheli Ckll. . $\quad . \quad$. $\quad . \quad$. $\quad . \quad$. $\quad .68$

Trionymus grindeliae Ferris . . . . . . . . . . $\quad .68$

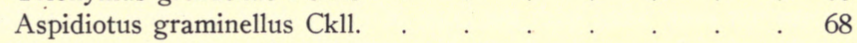

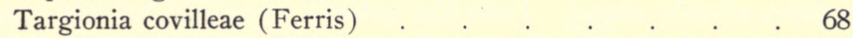




\section{INTRODUCTION}

The material upon which this paper is based was for the most part obtained by the author in the course of an extended tour through the arid, southwestern portion of the United States. This tour was undertaken for the purpose of investigating the distribution and abundance of a lac-producing scale insect, Tachardia larreae (Comstock), and the facts concerning this particular species will be presented in another paper. In addition to the species thus obtained a few others coming from other sources but either occurring in this area or having some direct connection with species occurring there are included. For most of the material of this class acknowledgments are due to Professor Cockerell.

The author has elsewhere expressed the belief that more may now be accomplished in the study of the Coccidae by the redescription of many of the named forms than by the naming of new species. This paper, therefore, is presented not only for the purpose of recording new forms but even more with the hope of elucidating as many as possible of species already named. From the author's viewpoint the new species, considered merely as such, are but an interesting by-product of the study.

The types of all the new species herein described are deposited in the collection of Coccidae of the Department of Entomology of Stanford University. In all cases a holotype has been designated.

In the arrangement of the genera the Fernald Catalogue of the Coccidae has in general been followed, except in cases where that arrangement is obviously artificial. In the case of species listed in this catalogue and its various supplements no references are given unless a change in name is here made. 


\section{SYSTEMATIC TREATMENT}

\section{Genus PALEOCOCCUS Ckll.}

Fig. 1.

Monophleboid Coccidae of the general type of the genus Icerya; adult female possessing a marsupium in which the eggs are deposited and in which they remain untib hatching, this marsupium formed by the invagination of a portion of the venter of the abdomen (Fig. 1A) and communicating with the exterior by a large, circular, non-contractile opening situated just behind the posterior pair of legs (Fig. 1B). Before the emergence of the larvae this opening is closed by a secretionary

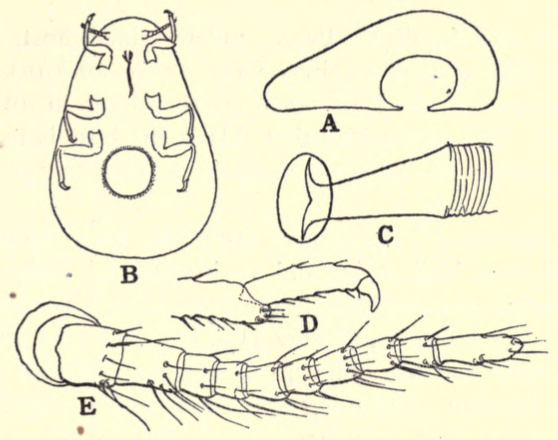

Fig. 1.-Paleococcus, morphological details: A, diagrammatic, vertical, longitudinal section through an adult female to show position of marsupium; B, diagram of ventral side of body of adult female to show position of opening of marsupium; C, spiracle; D, foot; E, antenna of $P$. morrilli.

flap which originates from the pores at the edge of the opening. Three pairs of abdominal spiracles are present, these all of a simple type (Fig. 1C), situated at the posterior end of the abdomen. Antennae ten to eleven-segmented. Anal tube lacking in all stages except the first, in this stage very small. First stage larva as in Icerya and development as in that genus. 
Notes: As far as may be judged from the literature available to me for examination it remains to be demonstrated that any of the American species now referred to this genus are congeneric with the type. In none of the descriptions of the type species that $I$ have seen is any mention made of the presence of the marsupium or of the opening of the marsupium (erroneously described heretofore as the vaginal opening) which is the salient character of the genus as represented by the three species, $P$. townsendi (Ckll.), $P$. plucheae (Ckll.) and $P$. morrilli Ckll. Should it prove that these three are indeed not congeneric with $P$. fuscipennis (Burm.), the genus Crypticerya, with $P$. rosae (Riley \& Howard) as type, might be revived for them.

In all respects this genus is very close to Icerya, the only significant difference being found in the presence of the marsupium. In the immature stages the marsupium is not developed and specimens are not at all distinguishable from specimens of Icerya of corresponding age. The ring of pores which forms the margin of the opening of the marsupium is apparently homologous with the ring of pores by which the ovisac is formed in Icerya and the marsupium itself is homologous with the area included within this ring of pores.

\section{Paleococcus morrilli Ckll.}

Fig. 2.

Type host and locality. From undetermined host, Jerome, Ariz. In material of this species received from Professor Cockerell there remained a fragment of the host plant which agrees in all respects with Acacia greggii. The probability that this is the host is increased by the fact that the species has been taken from Acacia greggii on two other occasions.

Material examined. Specimens from the type material and from Acacia greggii, near Vail, Ariz., and at Cottonwood, Ariz., the latter collected by $\mathrm{E}$. Bethel and received by the author from Profẻssor Cockerell.

Habit. A large species, about $7 \mathrm{~mm}$. long, $4.5 \mathrm{~mm}$. high and $5 \mathrm{~mm}$. broad, high convex and somewhat pyriform, the posterior portion broadest; dark gray in color (becoming red when dried), slightly dusted over with white secretion and with longitudinal rows of short, white tufts of secretion.

Morphological characteristics. Adult female with the dorsum sparingly beset with small spines and setae which become longer and more numerous on the head. Margins with a series of large, stout setae, arranged singly, each accompanied by two or three short, stout spines. On the abdomen these groups of setae and spines are arranged segmentally. Depression containing the anal opening surrounded by many slender setae. Derm with relatively few pores, these all small and of one size and type and tending at intervals to form clusters which coincide with the tufts of secretion. Ventral side of the abdomen with numerous short 
spines of various lengths. Margin of the marsupial opening with numerous pores mingled with a few short spines.

Immature stages lacking the marsupium. Penultimate stage with numerous clusters of short, stout spines on the dorsum. First stage of larva (Fig. 2) of the type found in Icerya.

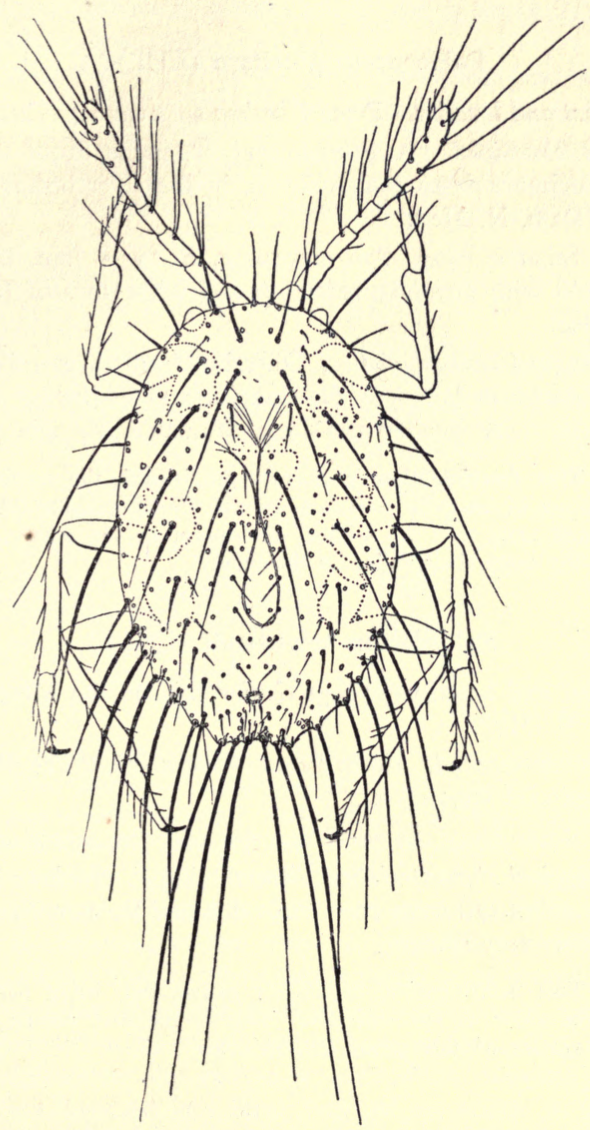

Fig. 2.-Paleococcus morrilli Ckll.: first stage larva. 
Notes: In the original description of this species it is stated that the body tapers posteriorly into a tail. It is in fact the anterior end that tapers, this being due in part to the natural form and in part to the fact that the abdomen when full of ova shrinks less than does the anterior portion of the body. This differs from the other species of this genus herein dealt with by the very stout marginal setae. The immature stages very much resemble the immature stages of Icerya rileyi, but may be distinguished by the groups of stout spines on the dorsum.

\section{Paleococcus plucheae (Ckll.)?}

Type host and locality. From Pluchea sp. near Las Cruces, N. Mex. Material examined. A fragmentary specimen from the type material and specimens from Baccharis sp. in the river bottom below Elephant Butte Dam, N. Mex.

Habit. Smaller than the preceding, 5 to $6 \mathrm{~mm}$. long. Rather thickly covered with powdery secretion and with rows of tufts, all of a yellowish color.

Morphological characteristics. Differing from $P$. morrilli only in the much more abundant pores of the dorsum and in having the marginal setae noticeably more slender and not accompanied by short spines.

Notes: This determination is entirely provisional, the specimen from the type material being in too poor condition to aid in recognizing the species. The specimens at hand agree with the original description in the color of the secretion and are from the same river valley as the types.

\section{Paleococcus townsendi (Ckll.)?}

Type host and locality. From Gutierrezia on the Mescalero Indian Reservation, N. Mex.

Specimens examined. From Peucephyllum schottii at Shaver's Well, a few miles east of Mecca, Cal.

Habit. Resembling the preceding but with the secretion pure white.

Morphological characteristics. Resembling $P$. plucheae in abundance of dorsal pores but differing from both this and $P$. morrilli in having all spines and setae very slender.

Notes: This determination is entirely provisional, being based only upon similarity in the color of the secretion. This is the first record of the occurrence of any species of this genus in California. 


\section{Genus ICERYA Sign.}

Fig. 3.

Ordinarily but little attention seems to have been paid to morphological characters (other than the antennae and legs) in describing species of this genus. A study of the material available, representing five species, indicates that these species, at least, can quite easily be separated by morphological characters.

These characters are to be found in the spines and setae and the various pores. The shape and size of the setae and their arrangement, whether in tufts or singly, are very useful. In I. purchasi, for example, the setae are very abundant, all slender and in part arranged in conspicuous tufts. In I. rileyi the setae are few and are not arranged in tufts.

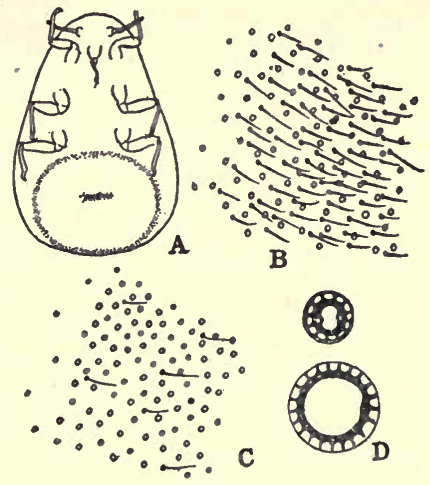

Fig. 3.-Icerya, morphological details: A, diagram of ventral side of female to show position of ring of pores from which the ovisac is excreted; $\mathrm{B}$, portion of ventral pore ring of $I$. rileyi; $\mathrm{C}$, portion of ventral pore ring of $I$. purchasi; D, types of dermal pores.

Two types of pores are found in the genus (Fig. 3D). These are very similar in appearance, but those of one type are nearly twice as large as those of the other. The relative numbers of these two types are of value, $I$. rileyi having all the pores of the smaller type, while in $I$. seychellarum there are many of the larger type as well. The arrangement of the pores by which the ovisac is secreted is especially significant. These pores are disposed in a large ring on the venter of the abdomen (Fig. 3A), this ring enclosing an area in which pores and spines are practically lacking. In $I$. rileyi (Fig. $3 \mathrm{~B}$ ) the pores are very numerous and are associated with a nearly equal number of short spines. In $I$. 
purchasi (Fig. 3C) the ring contains many pores and but very few spines. In I. seychellarum (specimens from Ceylon, determined by $\mathrm{E}$. E. Green) the pores are few and anteriorly the ring almost disappears.

I have elsewhere recorded the presence of abdominal spiracles in the females of certain species of this genus, but, as far as I am aware, they have not been recorded in the male. In fact, I do not know that they have been seen in the male of any Coccid. There are three pairs in the male of $I$. rileyi, these being on the last three segments of the abdomen.

\section{Icerya rileyi Ckll.}

Fig. 3B.

Type host and locality. From Covillea and Prosopis, Mesilla Valley, N. Mex.

Specimens examined. From Covillea glutinosa near the Mesilla Valley and Socorro, N. Mex., and from Prosopis, velutina near Benson, Ariz.

Habit. Dorsum with a few irregular tufts of secretion. Ovisac quite long, more or less cylindrical, minutely ridged but not fluted, white or slightly yellowish at the base.

Morphological characteristics. Dorsum of the adult female rather sparingly beset with spines and setae of various sizes, some short and stout, others long and slender, these nowhere arranged in tufts. Margins with a series of long, slender setae arranged in twos or threes, the groups on the abdomen being disposed one to each segment. Setae about the anal opening rather small and stout, few. Pores throughout of but one size, small, those of the ventral ring very numerous and accompanied by a nearly equal number of short spines, those of the dorsum relatively few, showing some tendency to form groups at intervals. Three pairs of abdominal spiracles present, these at the posterior end of the abdomen. Antennae, nine to ten-segmented.

The adult male (specimens from Prosopis velutina, at Benson, A riz.) appears to be of the type common to the genus. It possesses three pairs of abdominal spiracles, these on the last three segments.

Notes: The specimens from Prosopis velutina differ somewhat from the others in having the ovisac slightly yellowish at the base, agreeing in this respect with the description of $I$. littoralis Ckll. Otherwise I am unable to detect any difference between these and the specimens from the type host and locality.

Cockerell has named the subgenus Proticerya with this species as the type, basing this upon the nine-segmented antennae of the adult female. In some of my specimens the antennae are nine-segmented on one side of the body and tensegmented on the other. As some of the species of Icerya that normally have eleven-segmented antennae may in all probability at times vary to ten segments, it hardly seems that this subgenus is worthy of recognition, at least on the basis of this character alone. 


\section{Genus STOMACOCCUS Ferris.}

\section{Stomacoccus platani Ferris.}

1917. Stomacoccus platani Ferris, Can. Ent., 49 :375-8, fig. 36-39.

Type host and locality. From Platanus racemosa, Stevens Creek, Santa Clara County, Cal., and from the same host at Pasadena, Cal.

Material examined. From Platanus wrightii, Sabino Canyon, Tucson, Ariz., June 25th.

Notes: This species has not previously been recorded from any point outside of California. I am informed that it occurs on "Oriental Sycamore" at Fresno, in this state.

\section{Genus XYLOCOCCUS Loew. ·}

\section{Xylococcus macrocarpae Coleman.}

Professor Cockerell has sent me specimens of this species from $\mathrm{Li}$ bocedrus decurrens at Julian, sixty miles northeast of San Diego, Cal., collected by $\mathrm{E}$. Bethel. This has been recorded from the same host before, but not south of the central part of the state.

\section{Genus ORTHEZIA Bosc.}

\section{Orthezia nuda n. sp.}

Type host and locality. From Quercus emoryi, between Benson and Dragoon, Ariz., June 28, 1918.

Habit. Length of dried specimen with ovisac $4.5 \mathrm{~mm}$. ; length of ovisac $2.5 \mathrm{~mm}$., width $2.5 \mathrm{~mm}$. Dorsum entirely destitute of secretion except for a fringe of very short marginal tufts about the posterior portion of the abdomen. Ovisac as broad as long and but little longer than the length of the body, straight and with the tip truncate; composed of numerous narrow plates of rather loose secretion.

Morphological characteristics. Dorsum entirely destitute of spines except for a very few on the head between the antennae. Lateral margins of each abdominal segment, except the first, each with a small area; a small area behind each thoracic spiracle; a small area just caudolaterad and one just caudomesad of each posterior coxa. Ring of spines and pores from which the ovisac arises well defined. Antennae eight-segmented. Seven pairs of abdominal spiracles present.

Notes: The complete absence of secretion on the dorsum and the short, stout ovisac seem to distinguish this from any described species. 


\section{Orthezia graminis Tinsley.}

Type host and locality. From grass, Organ Mountains, N. Mex.

Material examined. From undetermined perennial grass near Lancaster, Los Angeles County, Cal.

Notes: This determination is based entirely upon the original description. While I am certainly not prepared to say that this species is identical with $O$. insignis, I am unable to find any characters by which my specimens can be separated from the latter species, even upon a direct comparison.

\section{Orthezia annae Ckll.}

Type host and locality. From Atriplex canescens, Las Cruces, N. Mex. Recorded from chenopodiaceous plants throughout the southwest.

Specimens examined. From Kochia californica, near Lancaster and Atriplex sp. near Lone Pine, Cal.; Atriplex sp. at Tempe and between San Simon and Bowie, Ariz. Professor Cockerell has sent me specimens from Atriplex sp. at Cottonwood, Ariz., collected by E. Bethel.

Notes: This species is very much in need of redescription, but I leave it for the present in the hope of presenting later a paper dealing especially with this group.

\section{Orthezia sp.}

An undetermined species of this genus was taken from Juniperus pachyphloea near Datil, N. Mex. I record this, as it appears to be one of the few (if indeed not the only) records of an Orthezia from a coniferous host.

\section{Genus LECANIODIASPIS Targ.}

\section{Lecaniodiaspis rufescens (Ckll.)?}

Type host and locality. From Atriplex, near Las Cruces, N. Mex. Specimens examined. From Adelia neomexicana and Chrysothamnus mohavensis at Lancaster, Los Angeles County, Cal., and from Adenostoma fasciculatum at Sierra Madre, Cal., the last collected by Professor Doane.

Morphological characteristics. The only characters of specific value seem to lie in the apparent absence of stigmatic spines and in the presence of five pairs of cribriform plates on the venter of the abdomen. The absence of stigmatic spines may be due to their loss in the course of preparation, but several individuals have been examined. Furthermore, no trouble of this sort has been experienced in dealing with other species of this genus.

Notes: This determination is provisional only, being based entirely upon the fact that other authors have determined the species found on Adenostoma as $L$. rufescens. 


\section{Lecaniodiaspis sp.}

Host and locality. From Holacantha emoryi, eight miles west of Ludlow, Cal.

Habit. Test in all respects resembling that of L. rufescens, oval, about $3 \mathrm{~mm}$. long and $2.5 \mathrm{~mm}$. wide, with a few slightly elevated points on the dorsum, white to yellowish.

Morphological characteristics. Stigmatic spines present only in connection with the anterior pair of spiracles, large, variously misshapen, appearing either singly or in pairs. Three pairs of cribriform plates present, these corresponding to the posterior three of other species.

Notes: The existing descriptions of all the American species of this group are inadequate for purposes of identification and as this may well be a described form I refrain from giving it a name. It is certainly not the species here recorded as L. rufescens.

\section{Genus OLLIFFIELLA Ckll.}

Coccidae referable to the sub-family Dactylopiinae (of the Fernald Catalogue), belonging to the Eriococcus group and probably most nearly related to the genus Kermes. Adult female with well developed legs and antennae, the latter five to six-segmented; without anal lobes; anal ring apparently hairless, borne at the inner end of a short invagination; derm with 8-shaped pores; tubular ducts very minute, of the type found in Eriococcus and related forms. First stage larva with well developed anal lobes; with rows of dorsal spines; with six-segmented antennae; with six hairs on the anal ring.

\section{Type of the genus, Olliffiella cristicola Ckll.}

Notes: When this genus was first described it appears to have been regarded as most closely related to some of the strange gall-making forms of Australia, but Cockerell has since assigned it to the Eriococcus group, a position that is in all probability correct. In its immature stages (except for the presence of the 8-shaped pores) $O$. cristicola is scarcely, if at all, separable generically from the corresponding stages of certain species of Kermes. The presence of 8-shaped pores is somewhat disturbing, but it should be noted that these pores are not as distinctive of the Asterolecaniine group as has been thought, being developed in some of the Monophleboid forms (Stigmacoccus asper) as well, and it hardly seems that this single character should outweigh all the other evidence. It should also be noted that Cockerell's statement that the tarsi are distinctly twosegmented is entirely erroneous. The tarsi present no abnormal characters.

\section{Olliffiella cristicola Ckl1.}

Fig. 4.

Type host and locality. From Quercus wrightii (which according to recent authorities is $Q$. pungens), N. Mex. 
Material examined. From Quercus emoryi, between Benson and Dragoon and in the mountains east of Rice, Ariz.

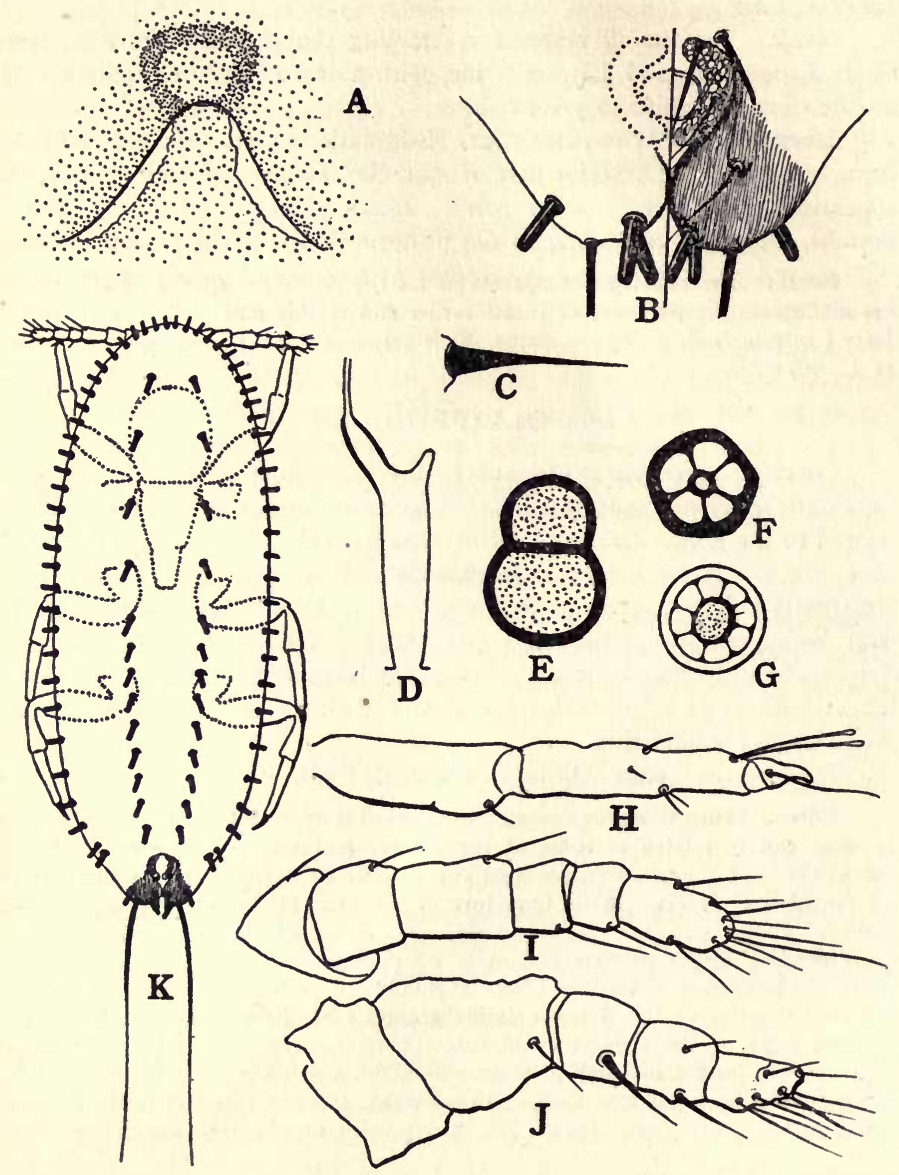

Fig. 4.-Ollifiella cristicola Ckll.: A, anal opening of adult female; B, anal lobes of first stage larva, right half dorsal, left half ventral; $C$, spine from dorsum of adult female; D, tubular duct; $E$, eight-shaped pore; $F$, pentagonal pore; $\mathrm{G}$, circular pore; $\mathrm{H}$, tibia and tarsus of adult; $\mathrm{I}$, antenna of first stage; $\mathrm{J}$, antenna of adult; $\mathrm{K}$, first stage larva. 
Habit. Occurring in galls on the under side of the leaf, the gall opening on the upper side of the leaf by an elongate slit parallel to the midrib of the leaf. Usually there is but a single gall on each leaf, but there may at times be two. The galls are quite large, 10 to $15 \mathrm{~mm}$. high, 8 to $10 \mathrm{~mm}$. in greatest thickness at the base, compressed conical in form, tapering to a sharp point. After drying they are hard and woody. The insect quite fills the cavity of the gall and lies with its dorsum against the opening. The shape of the insect is conical, the heavily chitinized dorsum being flat, the membranous venter conforming to the shape of the cavity.

Morphological characteristics. Fully mature female with the derm of the dorsum heavily chitinized, that of the venter remaining membranous. Dorsum flat, circular in outline, anal opening at some distance from the margin. Before maturity is reached the derm is membranous throughout and it is while in this condition that the insect may best be studied. The derm of the dorsum is thickly beset with 8-shaped pores (Fig. 4E), mingled with a few more or less pentagonal pores (Fig. 4F) and a few small, basally swollen spines (Fig. 4C) which are most numerous about the margin, and with numerous slender setae just behind the anal opening. A few extremely minute tubular ducts (Fig. 4D) are present. Venter likewise with 8-shaped pores and also with numerous multilocular pores (Fig. 4G). Anal lobes entirely lacking. Anal opening at the inner end of a short invagination. In mature individuals the external opening of this invagination (Fig. 4A) is somewhat parabolic in outline. Antennae (Fig. 4J) five to six-segmented, short and stout. Legs (Fig $4 \mathrm{H}$ ) well developed, claw not toothed beneath, digitules of the claw, filiform, not knobbed at the tip.

First stage larva (Fig. 4K) with well developed anal lobes (Fig. 4B); anal ring on the ventral side, bearing six small setae; margin with a single row of short, stout, truncate spines, dorsum with two longitudinal rows of such spines; antennae (Fig. 4I) six-segmented, of the usual Eriococcine type.

\section{Genus ERIOCOCCUS Targ.}

A considerable quantity of material belonging to this genus is at hand, but most of the species cannot be identified and are left for some future time. Only those species are here recorded of which the identification is practically certain. Mr. Harold Morrison of the United States Bureau of Entomology and the present author have prepared a paper dealing with the North American species of this genus which it is hoped may some day be published, and the redescription of the species here recorded is left for that paper. 
Eriococcus bahiae Ehrh.

Type locality. From Eriophyllum (= Bahia) confertiflorum, Stevens Creek, Santa Clara County, Cal.

Material examined. Topotypes and specimens from Gutierrezia sp. on the mesa west of Las Cruces, N. Mex.

\section{Eriococcus gillettei Tins.}

Type host and locality. From Juniperus virginiana (now called J. scopulorum), Salida, Colo.

Material examined. The types and specimens from Juniperus pachyphloea a few miles west of Datil, N. Mex.

\section{Eriococcus tinsleyi Ckll.}

Type host and locality. From Atriplex canescens, Mesilla Park, N. Mex.

Material examined. The types and specimens from Atriplex sp. Springerville, N. Mex.

\section{Genus FONSCOLOMBIA Licht.}

\section{Fonscolombia yuccae n. sp.}

Fig. 5.

Type host and locality. From a broad-leaved Yucca near the head of Blue Canyon, west of Socorro, N. Mex.

Habit. Occurring at the base of the leaves; covered with more or less white, woolly secretion; insect, when denuded of secretion, bright red.

Morphological characteristics. Adult female (flattened on slide) $1.2 \mathrm{~mm}$. long, elongate oval in form (Fig. 5E). Legs and antennae well developed, the latter seven-segmented, of the usual Eriococcine type (Fig. 5A); claw without a denticle beneath. Dorsum sparingly beset with small, slender spines (Fig. 5G). Derm with numerous small, tubular ducts (Fig. 5C) of the usual Eriococcine type, ventrally with numerous pentagonal pores (Fig. 5E) in the region of the vaginal opening and with a nearly complete circle of such pores about each of the spiracles (Fig. 5D). Anal lobes weakly developed, each bearing one long and two or three very short setae. Anal ring on the ventral side, small, heavily chitinized, bearing six small setae (Fig. $5 \mathrm{H}$ ).

Immature female with shorter and stouter antennae (Fig. 5B) than the adult; without pentagonal pores on the venter; with the dorsum beset 
with six longitudinal rows of short, stout, basally swollen spines (Fig. 5F) instead of with slender spines.

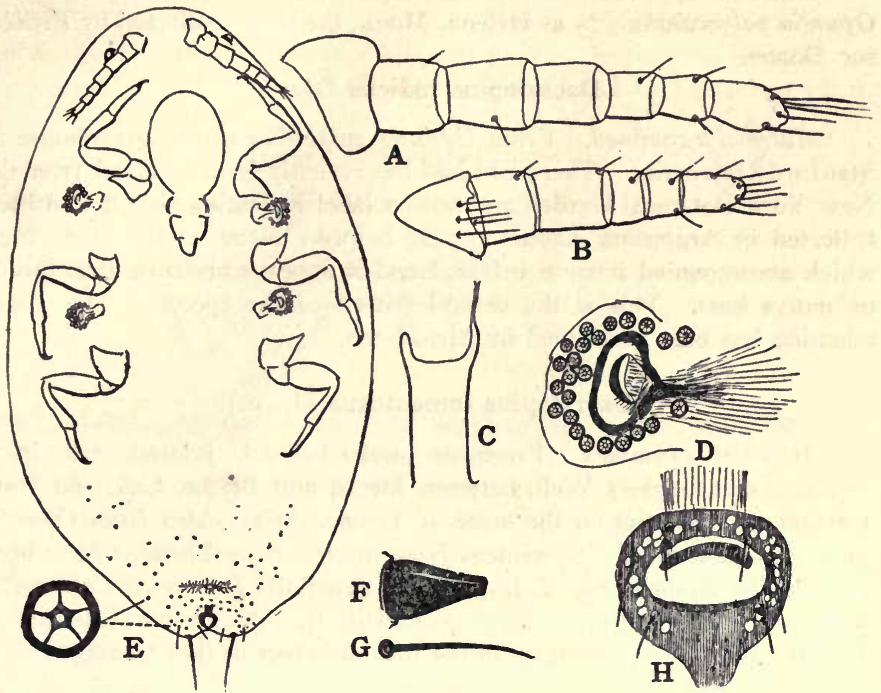

Fig. 5.-Fonscolombia yuccae n. sp.: A, antenna of adult female; B, antenna of immature female; C, tubular duct; D, spiracle of adult female; E, adult female from the ventral aspect and at the left a disproportionately enlarged ventral pore; $F$, spine of immature female; $G$, spine of adult female; $H$, anal ring of adult female.

Notes: This very closely resembles $F$. braggi Ckll. and Rob., differing chiefly in the fact that the adult female of the latter species lacks the pentagonal pores in the region of the vaginal opening. Through the kindness of Professor Cockerell I have been enabled to examine specimens from the type material of the latter species. It should be noted that in the description of this species the authors have mistakenly referred to the short, blunt spines as glands.

This is the second species of this genus to be described from North America, unless, as is quite possible, some of the species now referred to Gymnococcus belong here.

\section{Genus DACTYLOPIUS Costa.}

The determinations of the species of this genus are based upon a paper by Mr. E. E. Green ${ }^{1}$ dealing with the genus and also upon determinations made by $\mathrm{Mr}$. Green of specimens sent to him by me.

${ }^{1} 1912$. Green, E. E. "On the cultivated and wild forms of cochineal insects." Sn. Ec. Biology, $7: 79-92$, pl. 1. 
Dactylopius confusus (Ckll.).

Material examined. From a flat Opuntia at Tucson, Ariz., and from Opuntia polyacantha (?) at Helena, Mont., the latter collected by Professor Doane.

Dactylopius indicus Green.

Material examined. From Opuntia sulphurea in the greenhouse at Stanford University. This plant had but recently been received from the New York Botanical Garden and bore a label indicating that it had been collected in Argentina about a year before. None of the other cacti which accompanied it were infested and it appears probable that this is its native host. This is the second record of the species. The determination has been confirmed by Mr. Green.

\section{Dactylopius tomentosus (Lam.).}

Material examined. From an undetermined, jointed, cylindrical cactus at Gruendyke's Well, between Mecca and Blythe, Cal., and from a cylindrical Opuntia on the butte at Tempe, Ariz. Also from Opuntia sp. at San Diego, Cal. Specimens from the last named locality have been recorded by Essig in his "Injurious and Beneficial Insects of California" as $D$. confusus, but there is every probability that this record really has to do with tomentosus, which appears to be abundant in that locality.

\section{Genus PUTO Sign. \\ Puto yuccae (Coq.).}

1918. Puto yuccae (Coq.); Ferris, Cal. Species Mealy Bugs, p. 64.

What appears to be this species was taken from the crowns of $Y u c c a$ sp. at Magdalena, N. Mex.; Aster spinosus at Tucson, Ariz., and evening primrose a few miles north of Bishop, Cal.

\section{Genus PHENACOCCUS Ckll.}

Phenacoccus betheli (Ckll.).

Fig. 6.

\section{Ariz. \\ Type host and locality. From Amelanchier sp., Grand Canyon,}

Specimens examined. Part of the type material.

Habit. "Adult females solitary on the twigs; hemispherical or nearly; about $4 \mathrm{~mm}$. long, $23 / 4 \mathrm{~mm}$. broad, a little over $2 \mathrm{~mm}$. high; dark raspberry-red, covered dorsally with white mealy secretion in small tufts, 
like a deposit of alkali on the soil, the surface more or less visible between; short, thick, irregular marginal tufts": according to the original description.

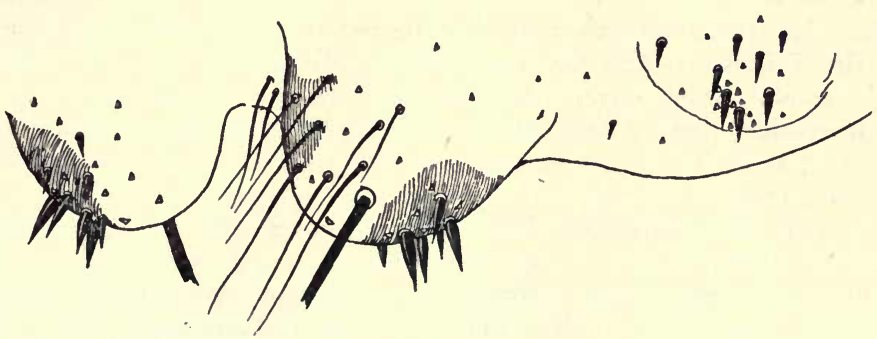

Fig. 6.-Phenacoccus betheli Ckll.: anal lobes and penultimate cerarius, left dorsal, right ventral.

Morphological characteristics. The number of pairs of cerarii is difficult to determine because of the distortion arising from the unusual convexity of the insect and the resemblance of the cerarian spines to those of the dorsum. Whether or not the eighteen pairs characteristic of this genus are present could only be determined by an examination of specimens taken before this convexity has been attained. Counting forward from the anal lobes I have been able to detect but six distinct pairs. Anal lobe and penultimate pairs with six to ten spines, third pair with two spines close together and several others scattered about, remainder with but two. In all the cerarii the spines are somewhat constricted at the base, giving them a "spearhead-shaped" appearance, those of the anal lobe pair largest, the others becoming successively smaller. All of the cerarii with but few pores and without auxiliary setae. Anal lobes with more or less irregular chitinization both dorsally and ventrally and with numerous long, slender setae on the ventral side. Spines of the dorsum of the body shaped like the cerarian spines and as large as the smaller of the latter, few, scattered. Tubular ducts all small and without a raised rim about the mouth. Anal ring setae considerably longer than the diameter of the anal ring and scarcely half as long as the anal lobe setae. Antennae eight to nine-segmented. Legs rather short, the claw with a distinct tooth.

Notes: The numerous spines of the last three pairs of cerarii and the long slender setae of the ventral side of the anal lobes are very distinctive features of this species. 


\section{Phenacoccus helianthi (Ckll.).}

Type host and locality. From Helianthus, Las Cruces, N. Mex.

Material examined. From Pluchea sp. and Solanum sp. at Las Cruces, N. Mex.; Baccharis sp. in the river bottom below Elephant Butte Dam, N. Mex.; undetermined composite near the University at Tucson, Ariz.; Ptiloria sp., near Lancaster, Los Angeles County, Cal.

Habit. Thinly covered with white, powdery secretion, lateral tassels equaling perhaps half the width of the body, caudal tassels nearly as long as the body. At maturity forming a slender, white ovisac 5 to $10 \mathrm{~mm}$. long.

Morphological characteristics. With eighteen pairs of cerarii. Anal lobe pair with ten or more cerarian spines and numerous but scattered pores, all surrounded by a distinct but not sharply delimited chitinized area; penultimate pair with five to eight spines and numerous pores; remaining pairs all with but two spines and a cluster of eight to ten pores except for the first two or three pairs, which have four to six spines. None of the cerarii with auxiliary setae. In all, the cerarian spines are rather stout, sharply pointed and slightly constricted at the base. Ventral side of the anal lobes without a chitinized area and with but two or three small setae. Spines of the dorsum of the body few, small, in part slender and in part like the cerarian spines but smaller; not forming a small, median cluster on the last segment. Tubular ducts abundant, small without a raised rim about the mouth. Anal ring of normal size and shape, the setae somewhat longer than the diameter of the ring and about equaling the anal lobe setae.

Notes: This is very close to $P$. eriogoni Ferris, so close that the figure given for the latter species will apply equally well for $P$. helianthi. The two differ in habit in the fact that the marginal tassels of helianthi are long and slender, while in eriogoni they are short and stout. Morphologically the two differ in the fact that eriogoni possesses six to eight spines in all the cerarii and appears constantly to have a small cluster of spines (not noted in the original description) on the dorsum of the last abdominal segment. These differences are quite small, but they are constant throughout my material.

\section{Genus HETEROCOCCUS Ferris.}

Heterococcus arenae Ferris.

1918. Heterococcus arenae Ferris, Cal. Species Mealy Bugs, p. 65, text fig. 16C, pl. 3, fig. 32.

Type host and locality. From Poa douglasii on the sand dunes at $\mathrm{Pa}-$ cific Grove, Monterey County, Cal.

Material examined. From an undetermined species of perennial grass at the top of the mountain on the road between Big Pine and Deep Springs, Inyo County, Cal. Altitude about 7,000 feet. 


\section{Genus LACHNODIUS Maskell.}

This genus was based upon the fact that the anal ring bears numerous (twenty or more) setae instead of the six to eight commonly found in members of the Pseudococcus group. I have at hand a specimen from Australia, determined by Froggatt as L. eucalypti (Maskell), the type of the genus. Also, through the kindness of Mr. E. E. Green, I have specimens of $L$. greeni Vays. and a manuscript species of Green. I am also recording an apparently new species that I shall refer to this genus.

If the specimen purporting to be $L$. eucalypti be correctly determined, none of the other three species at hand can be referred to this genus. The anal ring possesses numerous setae, but the margin of the body is beset with a continuous, single row of short, sharp spines and the derm bears 8-shaped pores. I have been unable to detect with certainty whether the dorsal ostioles are present or not. I am inclined to think that they are not.

The other three species are unquestionably of the Pseudococcus group and should probably be separated from Pseudococcus. Being unable to determine the real nature of the genus Lachnodius I shall regard them as belonging to this genus and base the following characterization of the group upon them.

Pseudococcine forms in which the anal ring typically possesses more than six setae, sometimes as many as twenty or more. In cases where the number of setae on the ring is reduced the ring is surrounded by a cluster of setae. Anal ring tending to be set well away from the margin. Cerarii consisting typically of irregular patches of spines and pores; varying in number from eight to fifteen. Antennae seven to eight-segmented. First stage larva with six-segmented antennae and with six hairs on the anal ring.

Lachnodius salicis $\mathrm{n}$. $\mathrm{sp}$.

Fig. 7.

Type host and locality. From Salix sp., Sabino Canyon, Tucson, Ariz., June 25, 1918.

Habit. Occurring in cracks in the bark, attended by ants and concealed beneath a covering of papery consistency made by the ants. All the specimens found were bare of secretion (doubtless because of the attentions of the ants) except for a slight marginal fringe on the abdomen, and were of a chocolate color. So well were they concealed in the cracks that it was only the presence of the swarms of ants that led to their discovery. 
Morphological characteristics. Length (flattened on slide) $3 \mathrm{~mm}$; form broadly oval, almost circular. The number of pairs of cerarii is difficult to determine with accuracy, due to the fact that some of them appear to be divided, but it may be taken as seven. Of these, one pair,

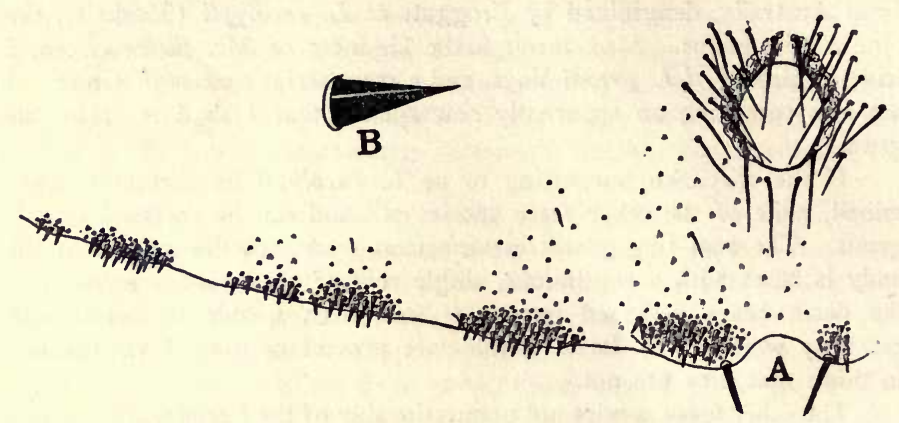

Fig. 7.-Lachnodius salicis n. sp.: A, dorsal aspect of portion of tip of abdomen, showing anal ring and cerarii; B, cerarian spine disproportionately enlarged.

containing five to seven closely grouped spines, is on the head anterior to the eyes. The remainder are along the posterior portion of the abdomen, the groups being somewhat linear in form. Anal lobe pair with fifteen to twenty spines, penultimate pair with nearly as many, the number in the remaining pairs becoming successively less. In all the spines are short and conical, accompanied by many pores but without auxiliary setae. Dorsal body setae relatively few, short and slender. Tubular ducts very few, small. Anal lobes protruding but little, without chitinization either dorsally or ventrally. Anal ring at some distance from the margin, of normal size and shape, bearing six to ten setae and surrounded by a group of setae. Antennae eight-segmented. Legs rather stout, the claw without a tooth.

Notes: This differs from the other species of its group by the reduced number of setae on the anal ring. In other respects, however, all three are very similar.

Genus PSEUDOCOCCUS Westw.

\section{Pseudococcus ephedrae (Coq.).}

Fig. 8.

1918. Pseudococcus cphedrae (Coq.); Ferris, Cal. Species Mealy Bugs, p. 45. Cal.

Type host and locality. From Ephedra sp., Los Angeles County, 
Material examined. From Ephedra sp., near Lancaster, Los Angeles County, and near Whitewater, San Bernardino County, Cal.

Habit. Covered with powdery, white secretion; lateral tassels short, caudal tassels long and stout. At maturity a pad of secretion is formed underlying the entire body and finally partially enveloping it.

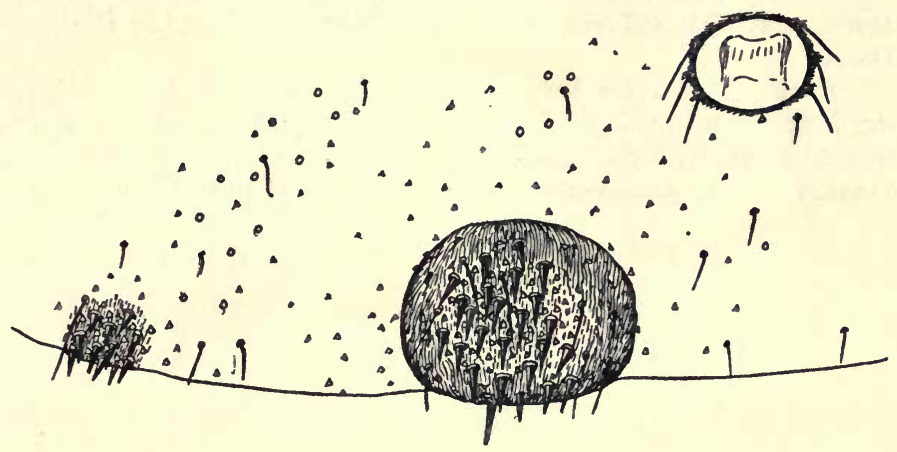

Fig. 8.-Pseudococcus ephedrae (Coq.) : dorsal aspect of portion of tip of abdomen, showing anal ring and anal lobe and penultimate cerarii.

Morphological characteristics. Length of largest specimens (flattened on slide) $5.5 \mathrm{~mm}$. Form broadly oval. Not more than eleven pairs of cerarii present, some of those normally present along the anterior portion of the abdomen and the posterior portion of the thorax being suppressed. Anal lobe pair with fifteen to twenty conical spines, several slender setae and numerous pores, all borne upon a circular, sharply defined and somewhat elevated, chitinized area. Penultimate cerarii with six to ten spines and scattered pores, but no slender setae, all surrounded by an indefinite chitinized area. Remaining cerarii with two to four spines and three to four pores, but no auxiliary setae. Dorsal body setae few, small and slender. Tubular ducts for the most part without a raised rim about the mouth. Anal ring simple, borne upon the dorsum at some distance from the margin. Anal ring setae scarcely as long as the diameter of the ring and about a third as long as the anal lobe setae.

First stage larva with six-segmented antennae; with but one pair of cerarii, these on the anal lobes and containing but two spines.

Notes: In my key to the California species of this genus this will run to $P$. crawii, a species which it very much resembles. However, the character and position of the anal ring are sufficient to distinguish it at once, the ring of crawii being in all respects of normal character. 


\section{Pseudococcus gutierreziae (Ckll.).}

Fig. 9.

Type host and locality. From Gutierrezia sarothrae between Las Cruces and Organ, N. Mex.

Material examined. From Gutierrezia sp., Deep Springs Valley, Inyo County, Cal., and near Sandy, Utah, the latter collected by Professor Doane.

Habit. Appearance before formation of ovisac not known; judging from the morphology of the insect the marginal tassels are all extremely short, with the caudal pair somewhat longer than the others. Ovisac very long and slender, reaching a length of 10 to $15 \mathrm{~mm}$.
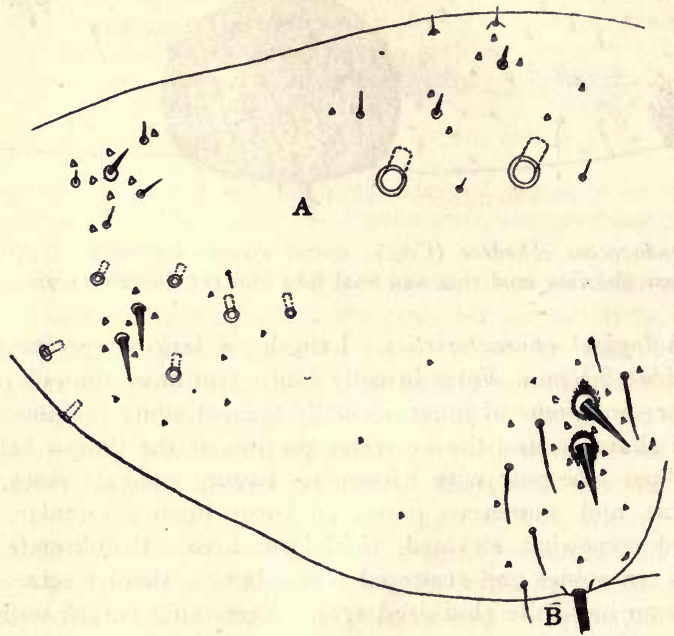

Fig. 9.-Pseudococcus gutierreziae (Ckll.): A, left half of the cephalic region; $B$, anal lobe and penultimate cerarii.

Morphological characteristics. Length (flattened on slide) 2 to $2.25 \mathrm{~mm}$. With not more than ten pairs of cerarii, sometimes with less, there being some variation even on opposite sides of the same specimen. The arrangement of the cerarii, however, appears to be constant in regard to certain points, there being none on the head anterior to the ocular pair. All the cerarian spines quite small and slender, those of the anal lobe cerarii (Fig. 9B) being largest. Ocular pair (Fig. 9A) with three to four very small spines, remainder with but two, all without auxiliary setae and entirely without grouped pores, except for the anal lobe pair in which there are two or three small setae and a few scattered pores. No 
chitinization of the anal lobes either dorsally or ventrally. Dorsal body setae few, small, slender. Tubular ducts very abundant, practically all with a raised rim about the mouth, those of the cephalic region conspicuously larger than the others. Anal ring setae about one and a half times as long as the diameter of the ring and about equal to the anal lobe setae. Anal lobe setae each accompanied by one or two smaller setae. Antennae seven to eight-segmented.

Notes: Morphologically this species is extremely close to $P$. eriogoni (Ehrh.), to which it will run in my key to the California species of this genus. The latter species, however, is not known to form a long ovisac and the two are possibly distinct. Assuming this to be the case the only definite character that I can find to separate the two is found in the fact that the tubular ducts of gutierreziae are much larger in the cephalic region than elsewhere, which appears not to be the case in eriogoni. Also, it appears that a much larger proportion of the ducts have a raised rim about the mouth in gutierreziae than in eriogoni, which is possibly correlated with the extreme development of the ovisac.

The description given here is based upon the specimens from Utah. The determination is based upon general resemblance and community of hosts.

\section{Pseudococcus irishi (Ckll.).}

Fig. 10.

1900. Dactylopius irishi Ckll., Can. Ent., $32: 129$.

1902. Erium irishi (Ckl1.); Ckll., Ann. Mag. Nat. Hist., (7) 10:466.

1903. Erium irishi (Ckll.); Fernald, Catalogue Coccidae, p. 113.

Type host and locality. From Covillea glutinosa, on the butte at Tempe, Ariz.

Material examined. From Covillea glutinosa, on the butte at Tempe and at Tucson, Ariz., and at Gruendyke's Well, between Mecca and Blythe, Cal.

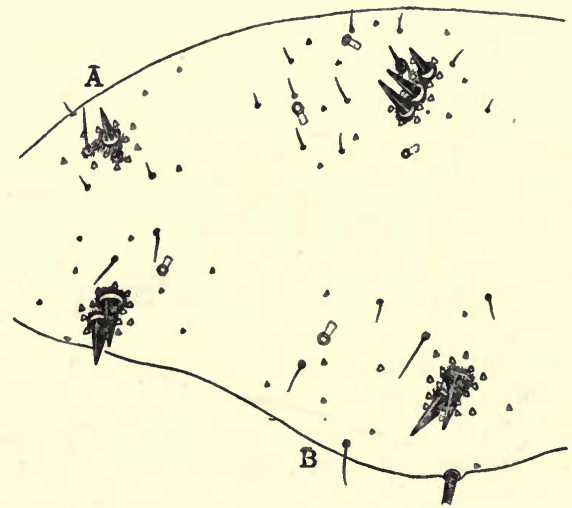

Fig. 10.-Pseudacoccus irishi (Ckll.): A, left half of cephalic region; B, anal lobe and penultimate cerarii. 
Habit. Before reaching maturity the insect bears short, slender marginal tassels; at maturity a rather broad, closely felted white ovisac 4 to $5 \mathrm{~mm}$. long is formed, the insect lying at one end of this and nearly enveloped by it. The specimens found at Tempe, Ariz., however, were all concealed in the interstices of a leafy gall which occurs quite frequently on Covillea, and the ovisac was not apparent.

Morphological characteristics. Length (flattened on slide) $2.5 \mathrm{~mm}$. Adult female with sixteen pairs of cerarii, these for the most part with but two spines, the first three to four pairs, however, having three to four spines, all without auxiliary setae and with a very small cluster of pores. Cerarian spines conical, stout, those of the anal lobe pair largest, the others but little smaller. Anal lobes without chitinization either dorsally or ventrally. Dorsal body setae all small, slender, few. Tubular ducts abundant, all of the same size and apparently all with a raised rim about the mouth. Anal ring setae scarcely longer than the diameter of the ring (which is rather small and relatively simple) and about half as long as the anal lobe setae. Antennae normally eight-segmented.

Notes: In my key to the California species of this genus this runs to $P$. sequoiae (Coleman). It differs from this species in having all the cerarian spines quite large and stout and accompanied by a small but definite group of pores, and in having tubular ducts with a raised rim about the mouth. It is very close to a species that I take to be $P$. steelii (Ckll.); the differences between these two will be discussed in connection with the latter species.

This is certainly not congeneric with Erium globosum, being in all respects inseparable from Pseudococcus.

Pseudococcus juniperi Ehrh.

Fig. 11.

Type host and locality. Recorded as from Juniperus virginiana, Ashforks, Ariz. This species of Juniperus does not occur in Arizona, the species that previously passed under that name now being known as J. scopulorum.

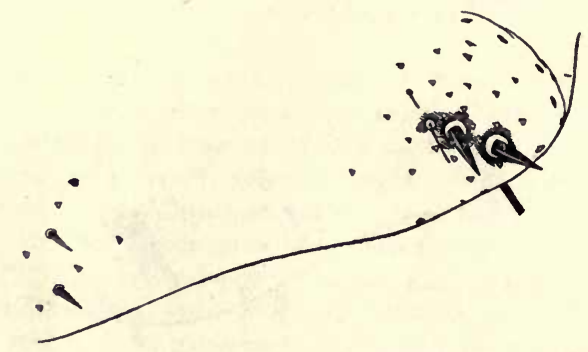

Fig. 11.-Pseudococcus juniperi Ehrh.: anal lobe and penultimate cerarii. 
Material examined. The type and specimens from Juniperus pachy. phloea, a few miles west of Datil, N. Mex.

Habit. Thinly covered with powdery secretion except for two narrow, longitudinal areas which are bare; marginal tassels practically lacking. Ehrhorn states that the egg-sac is small.

Morphological characteristics. Length (flattened on slide) $2 \mathrm{~mm}$. Form broadly oval, but tapering at both ends. The spines of the cerarii are extremely small and tend to be widely separated, making it difficult to determine the number of pairs, but there appear to be normally fifteen. In none of the cerarii are there auxiliary setae, nor is there any grouping of the pores about the cerarian spines. Anterior two to three cerarii with four to five spines, remainder with two. No chitinization of the anal lobes, either dorsally or ventrally. Dorsal body setae very few, extremely small, slender. Cylindrical ducts all small, without a raised rim about the mouth, not concentrated at the lateral margins of the abdominal segments. Anal ring setae somewhat longer than the diameter of the ring and nearly equaling the anal lobe setae. Antennae normally eightsegmented.

Notes: This is very similar to $P$. sequoiae (Coleman), which is common on Sequoia and various species of Cupressus in California. The chief differences are in the widely separated cerarian spines of juniperi and in the fact that the tubular ducts in this species are not at all concentrated at the lateral margins of the abdominal segments.

\section{Pseudococcus prosopidis (Ckll.).}

Fig. 12.

Type host and locality. From Prosopis sp. at Mesilla Park, N. Mex. Material examined. From Prosopis velutina near Tucson and near Benson, Ariz.

Habit. Dorsum almost entirely bare of secretion, marginal tassels very short, caudal tassels somewhat longer. At maturity a somewhat pad-like ovisac is formed.

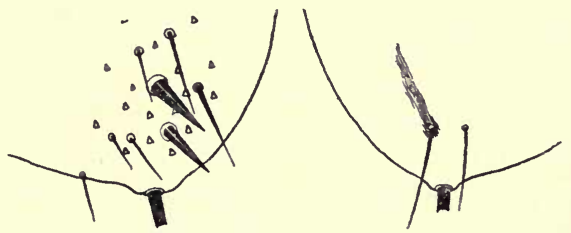

Fig. 12.-Pseudococcus prosopidis Ckll.: anal lobes, left half dorsal, right half ventral. 
Morphological characteristics. With about ten recognizable pairs of cerarii, the number varying somewhat, due to the fact that the spines of the cerarii along the anterior portion of the abdomen and in the thoracic region are so small and tend to be so widely separated that their identity is obscured. There appear to be no cerarii on the head anterior to the ocular pair. Ocular pair with three to four spines, the remainder with but two, all rather small, those of the anal lobe cerarii largest. Anal lobe cerarii with three to four slender setae and a few scattered pores, remainder without auxiliary setae and without grouped pores. No chitinization of the dorsal side of the anal lobes, but the ventral side with a narrow, chitinized bar extending in from the base of one of the two minor setae. Dorsal body setae few, all small and slender. Tubular ducts confined to the ventral side of the body, many with a raised rim about the mouth. Anal lobe setae about one and a half times as long as the diameter of the anal ring and somewhat shorter than the anal lobe setae. Antennae normally eight-segmented.

Notes: In my key to the California species of this genus this runs to $P$. eriogoni (Ehrh.), from which it differs most constantly in the absence of tubular ducts on the dorsum. From other species of the same group it differs in the presence of a chitinized bar on the ventral side of the anal lobes.

- This determination is based upon general resemblance and community of host.

\section{Pseudococcus lycii n. sp.}

Type host and locality. From Lycium sp., Cottonwood, Ariz.

Habit. The specimens at hand are not in such condition as to permit a description of the species in life. Judging from its morphology the tassels are quite distinct, but short and slender, the caudal pair not longer than the others.

Morphological characteristics. Length (flattened on slide) $3.5 \mathrm{~mm}$. Form broadly oval or nearly circular. Fifteen or sixteen pairs of cerarii present, each (including the anal lobe pair) with but two spines, a small but distinct cluster of pores and no auxiliary setae. Cerarian spines all of practically the same size, rather large, stout, conical, with the tip slightly flagellate. No chitinization of the anal lobes, either dorsally or ventrally. Dorsal body setae few, small, lanceolate. Tubular ducts confined to the venter, numerous, small and with a raised rim about the mouth, except for a single duct on each anal lobe and a few on the ventral side of the thorax which are much larger than the others and which do not have a rim about the mouth. Antennae very variable, six to eight. segmented. Claw with a distinct tooth. Anal ring setae about twice as long as the diameter of the ring and much longer than the anal lobe setae. Anal lobe setae accompanied by a single minor seta.

Notes: This is a rather peculiar species. The toothed claw is in general characteristic of the genus Phenacoccus, yet the species presents none of the other 
characters of that genus. The single large duct on the ventral side of each anal lobe and the other ducts of this type on the ventral side of the thorax are quite distinctive characters.

The material upon which the species is based was collected by $\mathrm{Mr}$. E. Bethel and transmitted to me by Professor Cockerell.

\section{Pseudococcus steelii (Ckll. and Towns.).}

Fig. 13.

1894. Bergrothia steelii Ckll. and Towns., Ent. News, 5 :263.

1894. Bergrothia townsendi var. steelii Ck11. and Towns.; Ck11., Ent. News, 5:282. 1902. Erium steelii (Ckll. and Towns.); Ckll., Ann. Mag. Nat. Hist. (7), $10: 466$. 1903. Erium steelii (Ckll. and Towns.); Fernald, Catalogue Coccidae, p. 113.

Type host and locality. From Covillea glutinosa (= Larrea mexicana), Mesilla Park, N. Mex.

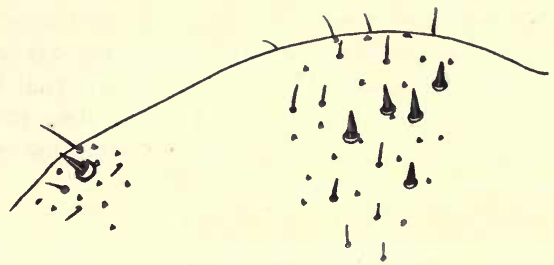

Fig. 13.-Pseudococcus steelii (Ckll. and Towns.) : left half of cephalic region.

Specimens examined. From Covillea glutinosa on the mesa near Mesilla Park, N. Mex.

In all respects this species is extremely close to $P$. irishi (Ckll.), differing not at all in habit and differing morphologically only in having a scattered group of spines on the head in the position of the first pair of cerarii. Compare Fig. 13 with Fig. 10A.

\section{Genus ERIUM Maskell.}

\section{Erium lichtensioides (Ckll.).}

1918. Erium lichtensioides (Ck11.); Ferris, Cal. Species Mealy Bugs, p. 75, pl. 3, fig. 25.

Specimens examined. From Artemisia sp. at Magdalena, N. Mex., and in Deep Springs Valley, Inyo County, Cal.

\section{Genus RIPERSIA Sign.}

The grass-infesting mealy bugs are a most puzzling group. Characterized in general by a reduction in the number of pairs of cerarii and in the number of antennal segments, it is possible to recognize a group of species having much in common, yet difficult to define this group in any 
but an arbitrary fashion. I have elsewhere pointed out that the genus Ripersia as usually understood is a most heterogeneous group and that our knowledge of the type species is insufficient to permit conclusions as to its real character. I now have at hand a species (herein described as Ripersia hilariae n. sp.) which is in all probability congeneric with the type of this genus. If we compare this species with the types of the genera Pseudococcus and Trionymus it is not at all difficult to point out wherein it is generically distinct. Nevertheless it is possible to form an almost complete series of species so effectually connecting these genera that the points at which these groups are to be separated become entirely a matter of opinion. Indeed, the series can be extended to connect in an unbroken chain such diverse forms as typical Phenacoccus and typical Ripersiella.

For the present I accept the genus Ripersia as composed of forms having the following characteristics:

Pseudococcine forms in which the cerarii are apparently entirely lacking or are reduced to a single pair, these on the anal lobes and with the cerarian spines setiform; with the anal ring tending to be simple and at some distance from the posterior margin of the abdomen; with the antennae normally six to seven-segmented.

\section{Ripersia hilariae n. sp.}

Fig. 14.

Type host and locality. From a perennial grass, probably Hilaria cenchroides, on the Jornada del Muerto, fifty-one miles north of Las Cruces, N. Mex.

Habit. Occurring beneath the sheathing bases of the leaves, surrounded by a small amount of secretion.

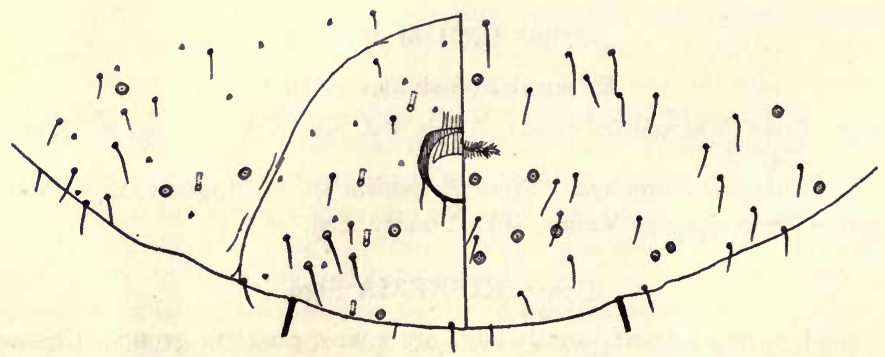

Fig. 14.-Ripersia hilariae n. sp.: posterior portion of the abdomen, left half dorsal, right half ventral. 
Morphological characteristics. Adult female (flattened on slide) 2 to $2.25 \mathrm{~mm}$. long; slightly pyriform, the anterior end pointed, the posterior end broadly rounded. Cerarii apparently entirely lacking, the anal lobe area bearing merely a few widely separated setae which are hardly or not at all separable from the body setae. Dorsum almost bare except for a few very small setae on the head and several rather large setae near the lateral margins of the last two abdominal segments. Venter also bare except for setae on the last two segments. Triangular pores and tubular ducts few, the latter all small and without a raised rim about the mouth. Venter with relatively few multilocular pores; dorsum of the abdomen with a few pores of this type. Anal ring on the dorsum at some distance from the posterior end of the abdomen, rather small and consisting of a simple, non-cellular ring. Anal ring setae scarcely as long as the diameter of the ring and about one-fourth as long as the anal lobe setae. Legs quite short. Antennae six-segmented.

Notes: It is not impossible that this is $R$. sporoboli Ckll. However, I am here describing a species that I place tentatively as sporoboli and if my determination of the latter be correct the two are distinct.

\section{Ripersia sporoboli Ckll. ?}

Type host and locality. From Sporobolus depauperatus, Arroyo Pecos, Las Vegas, N. Mex.

Material examined. From Sporobolus aeroides, Farmington, N. Mex.

Habit. On leaves and stems, enveloped in white secretion.

Morphological characteristics. In general closely resembling the preceding, but with the anal lobe cerarii present, containing two setiform spines which are set close together. Anal ring simple, apparently interrupted anteriorly. Antennae seven-segmented.

Notes: This is possibly not $R$. sporoboli. The determination is based entirely upon hosts and the specimens at hand have seven-segmented antennae, while according to the original description the antennae are six-segmented.

The material at hand was collected by Mr. E. Bethel and transmitted to me by Professor Cockerell.

\section{Genus CRYPTORIPERSIA Ckll.}

1918. Ferris, Cal. Species Mealy Bugs, pp. 73-4.

This genus differs materially from the genus Ripersia (as defined above) only in having the anal ring distinctly cellular. The possession of a complete sac is hardly to be regarded as a generic character, being due merely to an increase in the number of tubular ducts. 


\section{Cryptoripersia arizonensis (Ehrh.).}

1899. Ripersia arizonensis Ehrhorn, Can. Ent., $31: 5$.

1911. Eriococcus salinus Ehrhorn, Can. Ent., $43: 276$.

1918. Cryptoripersia salinus (Ehrh.); Ferris, Cal. Species Mealy Bugs, p. 74, pl. 3, fig. 30 .

Through the kindness of Mr. Ehrhorn I have been enabled to examine the type slides of both Ripersia arizonensis and Eriococcus salinus. The two are certainly identical. I may record the species from the roots of Elymus sp. at Fort Tejon, Cal.

\section{Genus ACLERDA Sign.}

\section{Aclerda ariditatis n. sp.}

Fig. 15.

Type host and locality. From a perennial grass, probably Hilaria cenchroides, on the Jornada del Muerto, fifty-one miles north of Las Cruces, N. Mex.

Habit. Occurring chiefly at the nodes of the stems, beneath the sheathing bases of the leaves. Surrounded by a small amount of secretion.

Morphological characteristics. Length of adult female $2 \mathrm{~mm}$. Form elongate, nearly parallel-sided, sometimes somewhat irregular. Derm membranous except for the posterior portion of the abdomen, which is heavily chitinized and presents a wrinkled appearance. Margin of the body, except for this chitinized portion, beset with small, tubercle-like spines (Fig. 15C), which are arranged in a single or irregularly double row (Fig. $15 \mathrm{H}$ ), their distance apart depending upon the age of the insect and the consequent expansion of the derm, these spines rounded at the tip, not pointed or "spearhead-shaped." Mingled with these spines are a few large tubular ducts of the type shown in Fig. 15G and slightly back from the margin is a row of such ducts (Fig. $15 \mathrm{H}$ ) accompanied by others of a much smaller size. On the chitinized portion of the abdomen the large ducts are very abundant and are irregularly distributed. Anal plate (Fig. 15F) entire, bearing several long setae. Ventral side of the abdomen with a median furrow, which is continuous with the anal cleft, and with the derm somewhat less wrinkled than on the dorsum.

First stage (Fig. 15A, E) of the type common to the genus.

Second stage ? Without appendages. Posterior end of the abdomen (Fig. 15D) chitinized, marked with numerous wrinkles which are more or less perpendicular to the margin. Anal cleft shallow, continuous with a shallow furrow on both dorsum and venter. Anal opening at some 
distance from the margin, very small and without setae; anal plate likewise small, without setae. Margin of the body destitute of spines except along the cephalic region and the chitinized portion of the abdomen.

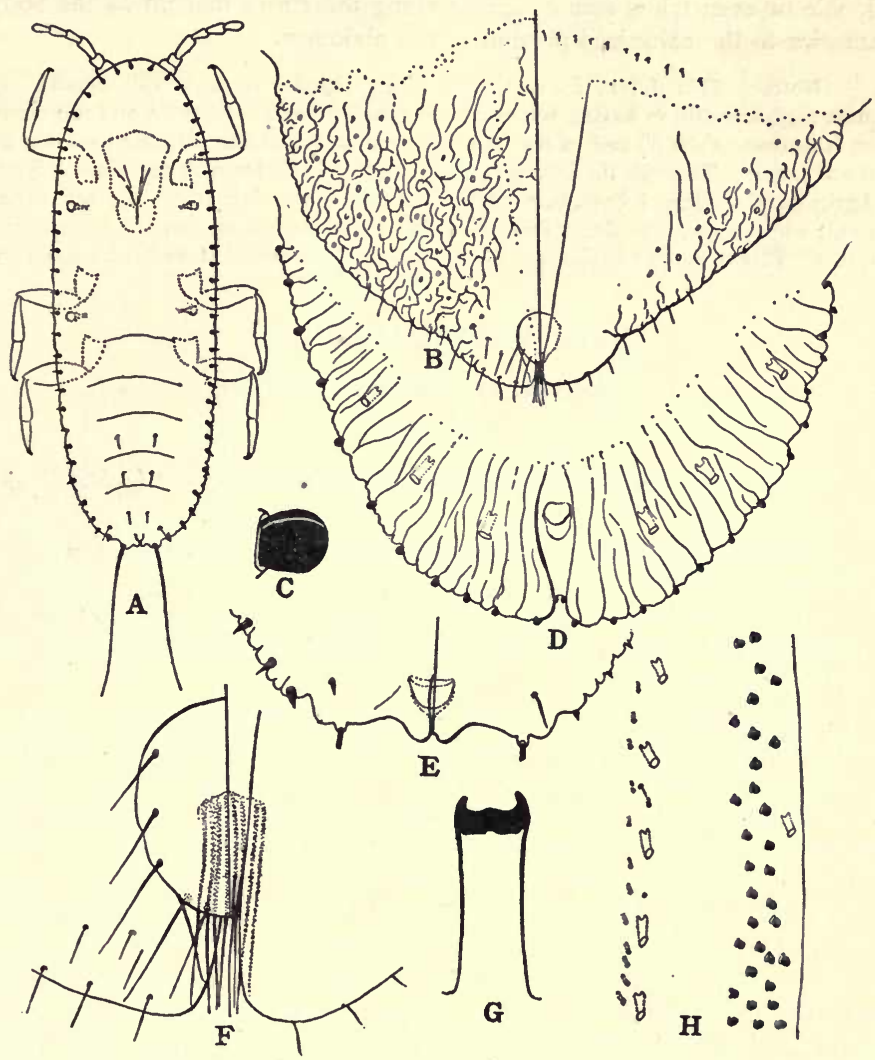

Fig. 15.-Aclerda ariditatis n. sp.: A, first stage larva; $\mathrm{B}$, posterior portion of abdomen of adult, left half dorsal, right half ventral; $\mathrm{C}$, marginal spine; $\mathrm{D}$, second (?) stage, dorsal aspect of posterior portion of abdomen; E, first stage, posterior portion of abdomen, left half dorsal, right half ventral; $F$, anal plate and tip of abdomen of adult, left half dorsal, right half ventral; G, tubular duct; $\mathrm{H}$, marginal and submarginal spines and pores of adult. 
Third stage ? Differing from the preceding in having the anal cleft deeper (much as in adult) and in having spines along a portion of the margin anterior to the chitinized portion of the abdomen.

Fourth stage ? Differing from the preceding chiefly in having a double or even triple row of spines along the entire margin of the body anterior to the chitinized portion of the abdomen.

Notes: This differs from A. californica (Ehrh.) in numerous details, but most conspicuously in having the marginal spines rounded at the tip and not acorn or "spearhead-shaped" and in the wrinkled appearance of the chitinized portion of the abdomen. Through the kindness of Professor G. A. Dean of the Kansas State Agricultural College I have been enabled to examine a slide of $A$. obscura (Parrott), which appears to differ from $A$. ariditatis in the entire absence of marginal spines. This is the third species of this genus to be described from North America.

\section{Genus PULVINARIA Targ. Pulvinaria bigeloviae Ckll.}

Fig. 16.

Type host and locality. From Chrysothamnus (= Bigelovia) sp., West Cliff, Colo.

Material examined. From Chrysothamnus sp., between Datil and Quemada, N. Mex.

Habit. Forming a white, rather irregular and somewhat fluted, slender ovisac, 5 to $10 \mathrm{~mm}$. long; ovisac not covering the dorsum; insect much shriveled when dry.

Morphological characteristics. Length (flattened on slide) 3 to 4 $\mathrm{mm}$. Form broadly oval. Derm membranous throughout, not pigmented. Stigmatic depressions almost or quite obsolete, and without differentiated spines, their position indicated merely by the pores of the stigmatic furrows. Marginal spines (Fig. 16C) small and slender, arranged in an irregular series. Anal cleft of ordinary depth. Anal plates (Fig. 16F) presenting no unusual characters; with four apical setae, which are close to the tip, two subapical setae and two fringe setae on each side, the outer of each pair the larger. Antennae (Fig 16E) normally eight-segmented. Legs well developed, the tarsus (Fig. 16B) curved, slightly shorter and somewhat narrower than the tibia. Digitules of the claw slender, but little expanded at the tip.

First stage larva (Fig. 16D) without stigmatic spines; marginal spines few, extremely minute; antennae (Fig. 16A) rather stout.

Notes: In the absence of differentiated stigmatic spines in both larva and adult this species departs from the usual characters of Pulvinaria. 

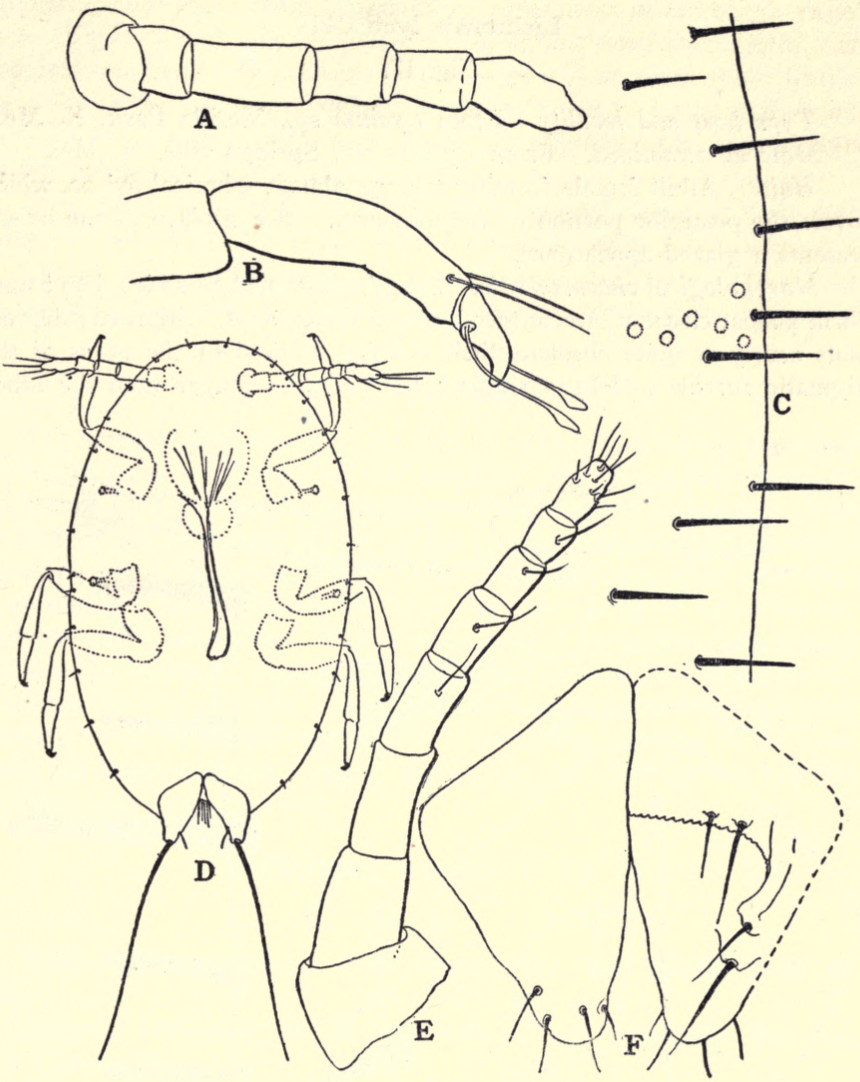

Fig. 16.-Pulvinaria bigeloviae Ckll.: A, antenna of first stage larva; B, foot of adult; C, marginal spines of adult in region of stigmatic depression; D, first stage larva; E, antenna of adult; F, anal plates, left half dorsal, right half ventral. 


\section{Genus LICHTENSIA Sign.}

\section{Lichtensia lycii Ckll.}

Fig. 17.

Type host and locality. From Lycium sp., Mesilla Park, N. Mex. Material examined. From Lycium sp., Springerville, N. Mex.

Habit. Adult female forming a large, almost spherical ovisac, which covers the posterior portion of the abdomen. The surface of the ovisac presents a glazed appearance.

Morphological characteristics. Length (flattened on slide) 4 to $5 \mathrm{~mm}$. Form almost circular. Derm membranous throughout. Stigmatic depressions nearly or quite obsolete, their position marked by the pores of the stigmatic furrow and by a single spine which is longer than the other

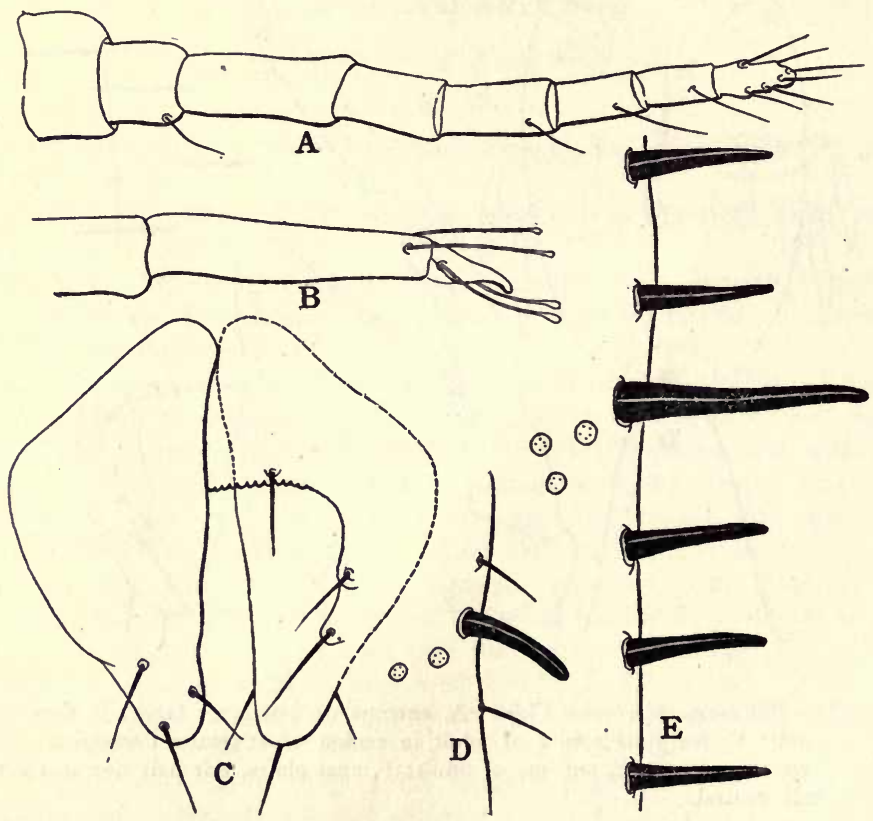

Fig. 17.-Lichtensia lycii Ckll.: A, antenna of adult female; B, foot of adult female; C, anal plates, left half dorsal, right half ventral; D, stigmatic and marginal spines of first stage; E, stigmatic and marginal spines of adult. 
marginal spines (Fig. 17E). Marginal spines rather large, quite close together and set in a definite, single row. Anal cleft rather short. Anal plates (Fig. 17C) of ordinary character, each with three apical setae, two subapical setae and with a single small fringe seta on each side. Antennae (Fig. 17A) long and slender, eight-segmented. Legs well developed, tarsus straight, nearly as wide as the tibia; digitules of the claw but little expanded at the tip (Fig. 17B).

First stage larva with a single large marginal spine in each stigmatic cleft and with very small, slender marginal spines (Fig. 17D).

Notes: This determination is based entirely upon general resemblance and community of host. No other species of this genus are available for comparison.

\section{Genus PHILEPHEDRA Ckll.}

The original description of this genus mentions few or no characters of generic value. The type of the genus, $P$. ephedrae (Ckll.), has the appearance of a much elongate Pulvinaria and departs structurally from the type of the latter genus only in the entire absence of differentiated stigmatic spines, differing in this respect, however, no more than does $P$. bigeloviae. Unfortunately no first stage larvae of $P$. ephedrae are available and a comparison of this stage cannot be made. The species described by Green as Philephedra theobromae has distinct stigmatic depressions, but the stigmatic spines appear to be but little differentiated. Whether it is truly congeneric with $P$. ephedrae remains to be seen. Green has suggested that it might possibly be the same species, but this unquestionably is not the case.

\section{Philephedra ephedrae (Ckll.).}

Fig. 18.

Type host and locality. From Ephedra sp., near Mesilla Park, N. Mex.

Material examined. From Ephedra sp., near Lancaster, Los Angeles County, Cal.

Habit. Before the formation of the ovisac the insect is quite flat and of a mottled pinkish and greenish color. At maturity it forms a smooth, white ovisac, 10 to $20 \mathrm{~mm}$. long, of firm texture, not at all covering the dorsum. Cockerell speaks of the presence of some white secretion on the dorsum, but this is not present in any of my specimens.

Morphological characteristics. Length (flattened on slide) 7 to 8 $\mathrm{mm}$. Width 2 to $2.5 \mathrm{~mm}$. Derm membranous throughout. Stigmatic de- 
pressions nearly or quite obsolete, their position indicated merely by the pores of the stigmatic furrows. Marginal spines (Fig. 18D) quite large and stout but sharply pointed, set quite close together and arranged in a very definite, single row. Anal cleft of ordinary depth. Anal plates (Fig.

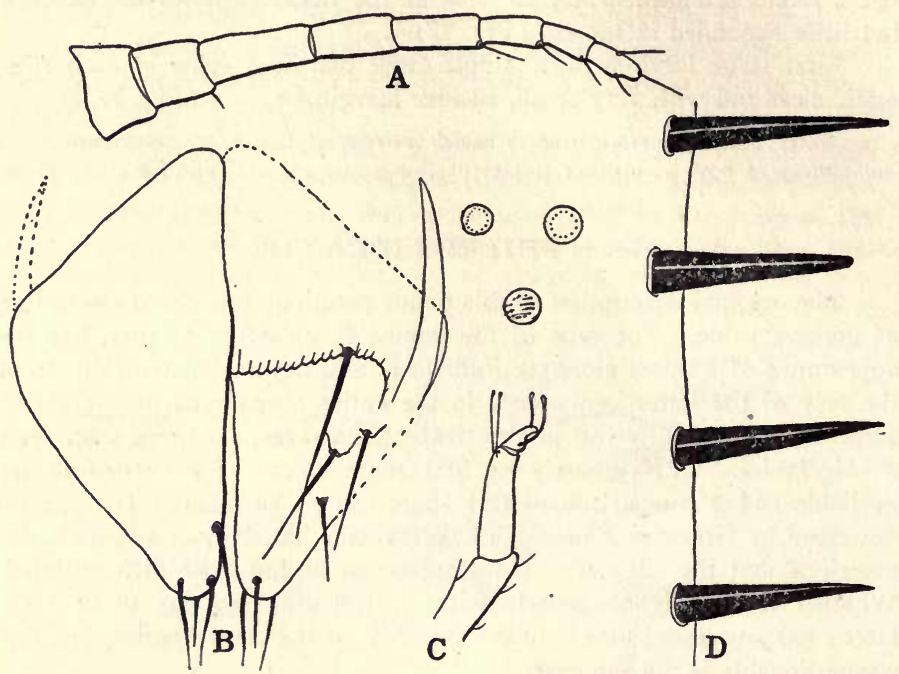

Fig. 18.-Philephedra ephedrae (Ckll.): A, antenna of adult female; B, anal plates, left half dorsal, right half ventral; $C$, foot of adult; D, marginal spines in region of stigmatic depression.

18B) of ordinary form, each with four apical setae, three subapical setae and with a single long fringe seta on each side. Antennae (Fig. 18A) long and slender, eight-segmented. Legs well developed, the tarsus (Fig. 18C) somewhat curved and slightly narrower than the tibia. Digitules of the claw slender, not greatly expanded at the tip.

Notes: This determination is based upon general resemblance and community of host. Unfortunately none of the eggs contained in the ovisacs hatched and the first stage larva cannot be described. 


\section{Genus CEROPLASTES Gray. \\ Ceroplastes irregularis Ckll.}

Fig. 19.

Type host and locality. On Sarcobatus (?) six miles north of Montezuma railroad station, Chihuahua, Mexico. Recorded from various species of Atriplex throughout the southwest.

Material examined. From Atriplex sp., near Las Cruces and Springerville, N. Mex.; Barstow and Lone Pine, Cal.; from Eurotia lanatum near Atolia, Cal.; from Atriplex confertifolia near Lancaster, Cal.

Habit. The specimens from Las Cruces and Springerville, N. Mex. (part of those from the former locality having been determined by Professor Cockerell as this species), are nearly hemispherical in form, 4 to $5 \mathrm{~mm}$. high and as many broad at the base, of a dark brown groundcolor variously mottled with white.

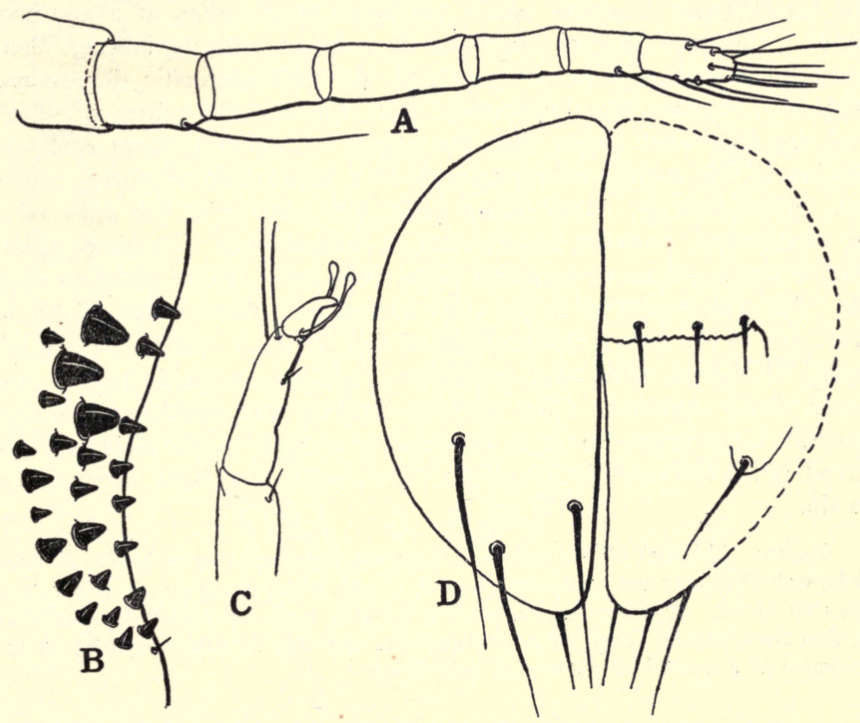

Fig. 19.-Ceroplastes irregularis Ckll.: A, antenna of adult female; B, spines of stigmatic depression; C, foot of adult; D, anal plates, left half dorsal, right half ventral. 
The specimens from Atriplex near Barstow and Eurotia near Atolia, Cal., are scarcely more than $2 \mathrm{~mm}$. high and are of a uniform dark brown color except for the apex, which is black. The secretion appears to be very thin.

The specimens from Atriplex near Lone Pine, Cal., are slightly larger than the preceding, are very irregular in form and have the groundcolor white, with brown or black markings about the base and at the apex.

The specimens from Atriplex confertifolia at Lancaster, Cal., are of about the form and shape of the New Mexico specimens, but are considerably smaller and vary from gray to brown in color.

Morphological characteristics. As far as may be determined from the material at hand all the above lots of specimens agree morphologically. The description is drawn from specimens from Las Cruces, N. Mex., which agree in all respects with specimens from the same locality determined by Professor Cockerell as this species.

At maturity the insect is very convex and the derm is heavily chitinized throughout. The anal plates are borne at the apex of a low projection. Posterior pair of stigmatic depressions entirely lacking, their presence not indicated in any manner. Anterior stigmatic depressions (Fig. 19B) shallow, beset with many short, tubercle-like spines, of which three are somewhat larger than the others. Extending from each depression to the corresponding spiracle is a broad belt of pores. Marginal spines lacking. Anal plates (Fig. 19D) borne at the apex of a low prominence, more or less circular in outline, each with three apical setae, a single subapical seta and three very small fringe setae on each side. (The statement as to the setae of the anal plates is very liable to error, due to the heavy chitinization of this region.) Derm, before becoming chitinized, with large numbers of small pores with heavily chitinized rims. Antennae (Fig. 19A) quite long and slender, seven-segmented. Legs large; tarsus at base nearly as wide as the tibia, slightly curved (Fig. 19C); digitules of the claw slender, but little expanded at the tip.

Notes: Although all the material examined appears to agree as far as morphological characters are concerned there is a very wide divergence in habit, as is indicated above. Whether we are dealing with at least three distinct species or whether these are all forms of a single species can only be determined by an examination of a much larger series of collections. 


\section{Genus CEROPLASTODES Ckll.}

\section{Ceroplastodes acaciae Ckll.}

Fig. 20.

Type host and locality. From Acacia paucispina (=A. constricta of Ckll)., Tucson, Ariz.

Material examined. From the type host and locality.

Habit. Covered by a test of pure white secretion, which bears numerous irregular nodules. Insect free within the test, shrinking to one end after oviposition.

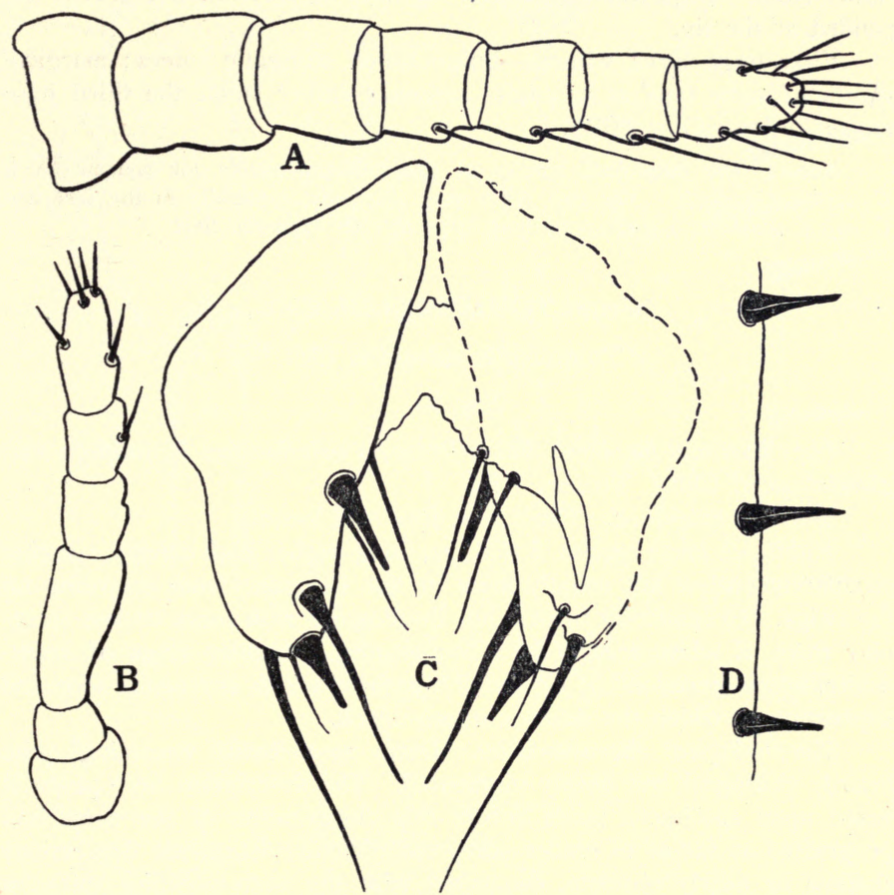

Fig. 20.-Ceroplastodes acaciae Ckll.: A, antenna of adult female; B, antenna of first stage; C, anal plates of adult, left half dorsal, right half ventral; D, marginal spines of adult. 
Morphological characteristics. Derm of the dorsum membranous, that of the venter more or less chitinized. In shrinking during the course of oviposition the body seems to fold but once, this fold occurring along a transverse line just in front of the middle pair of legs, the posterior portion of the body turning up at right angles to the anterior portion. Stigmatic depressions obsolete, their position indicated merely by a narrow belt of pores marking each stigmatic furrow. Marginal spines (Fig. 20D) small, sharply pointed, swollen at the base, arranged in a single, definite row. Anal plates (Fig. 20C) rather irregular in form, each with two stout spines and three slender setae and with two small fringe setae on each side. Antennae (Fig. 20A) seven-segmented, rather stout. Legs well developed; digitules of the claw not greatly expanded at the tip.

First stage larva without differentiated stigmatic spines; marginal spines of same type as in adult; antennae rather stout, the third joint unusually long (Fig. 20B).

Notes: The only other species of this genus available for comparison is C. cajani (Maskell). The two differ very markedly, especially in the fact that C. cajani possesses a single very long spine at each stigmatic cleft.

\section{Genus TOUMEYELLA Ckil.}

Toumeyella mirabilis Ckll.

Fig. 21.

Type host and locality. From Prosopis velutina (=P. juliflora var. glandulosa of Ckll.), Tucson, Ariz.

Material examined. From type host and locality.

Habit. A large species, 5 to $8 \mathrm{~mm}$. long, rather high convex, roughly circular in outline but usually more or less irregular from crowding on the twigs. Groundcolor brown, but the dorsum with more or less irregular rows of white areas (the "conspicuous irregular rings of snowwhite, waxy secretion" of Cockerell), each of which surrounds a central depression in which the derm is nearly black.

Morphological characteristics. Derm at maturity becoming quite heavily chitinized and deeply pigmented. The description here given is based upon specimens taken before this chitinization of the derm had progressed so far as to render study too difficult. Stigmatic depressions shallow or nearly obsolete, connected with the corresponding spiracles by a broad belt of pores. Stigmatic spines practically of same size and shape as the marginal spines (Fig. 21C), noticeable only because of their grouped position. Anal cleft of ordinary depth, the edges not 
fused. Anal plates (Fig. 21D) quite large, the cephalolateral margin slightly longer than the caudolateral margin, each plate with a large number of apical and discal setae and with three subapical setae. Hypopygial setae numerous. Derm of the dorsum with many large pores (Fig. 21B) which seem to consist of a heavily chitinized ring surrounding a less chitinized area, these pores occurring over the greater part of the posterior half of the dorsum anterior to the anal plates. In specimens in

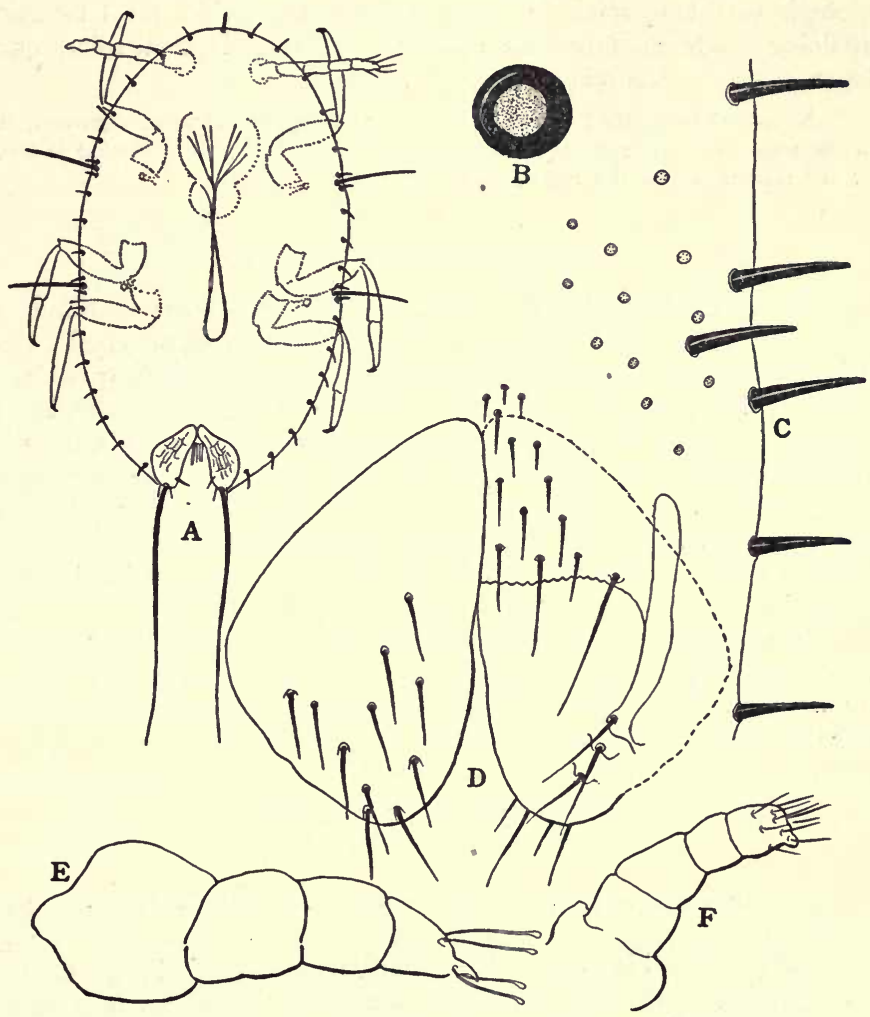

Fig. 21.-Toumeyella mirabilis Ckll.: A, first stage larva; B, dermal pore; C, marginal spines of region of stigmatic depression; $D$, anal plates, left half dorsal, right half ventral; E, leg of adult; F, antenna of adult. 
which the derm is still membranous there is nothing that appears to correspond with the white areas seen in adult specimens, but in specimens where the derm is heavily chitinized these areas are seen to consist of a non-pigmented region which surrounds a point of extra heavy chitinization. Antennae (Fig. 21F) very short and stout, five to six-segmented. Legs likewise very short and stout but with all the parts recognizable.

First stage larva (Fig. 21A) with two very small, stout spines and a single very long spine in each stigmatic depression, the long spine attaining nearly one-fourth the width of the body. Marginal spines quite large, slender. Anal plates slightly reticulated.

Notes: The original description is in error in the statement regarding the white areas on the dorsum, as has already been pointed out. It is further in error in the statement that the legs are lacking.

\section{Genus PROTODIASPIS Ckll.}

The original description of this genus is by no means as definite as might be desired and it is not at all certain that all the species now referred here are congeneric with the type. I am here naming two new species which I am referring for the present to this genus. Although it remains to be seen whether these are congeneric with $P$. paroula, there is, I think, but little room for question that they are strictly congeneric with $P$. anomala Green, an Australian species. It is an interesting point that the latter species is from a species of Acacia and that one of the new species is likewise from an Acacia and the other from a related genus, Prosopis.

Inasmuch as both the species here described were found only by the purest accident, being hidden away in cracks in the bark with nothing whatsoever to betray their presence, one can not but wonder how many more of these tiny species still remain to be discovered.

\section{Protodiaspis tridentata $\mathrm{n}$. $\mathrm{sp}$.}

Fig. 22.

Type host and locality. From Prosopis velutina, five miles east of Benson, Ariz.

Habit. Found in crevices in the bark, its presence indicated only by a roughening of the bark for which the insect is perhaps responsible. No scale secreted, but there is a small amount of cottony matter. Adult female contained within the derm of the preceding stage, which is heavily chitinized and black in color. Larval exuvium lying at one side, likewise black. Scale of male not observed. 
Morphological characteristics. Adult female about $.5 \mathrm{~mm}$. long, entirely enclosed by the second exuvium, which is heavily chitinized both dorsally and ventrally. Derm of the adult entirely membranous except for the posterior end of the body, which is heavily chitinized (Fig. 22A). From the dorsal aspect the pygidium (Fig. 22D) appears to be composed

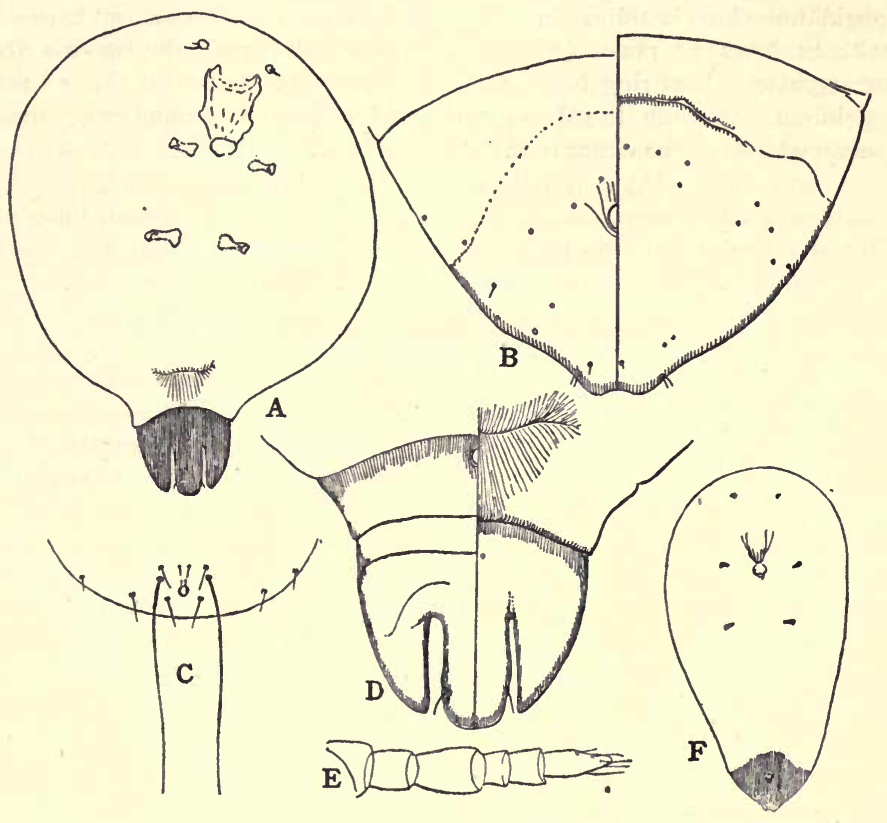

Fig. 22.-Protodiaspis tridentata n. sp.: A, adult female; B, pygidium of early second stage; C, posterior end of first stage; D, pygidium of adult; E, antenna of first stage; F, early second stage female.

of three segments, the first two together occupying about half of its length. First segment less heavily chitinized than the others and bearing the anal opening. Third segment deeply divided into three lobes, the middle lobe rounded at the tip, the others pointed. Middle lobe with a single small spine on each side near the tip. On the ventral side the chitinization appears to extend forward only to the posterior margin of the first dorsal segment. The vaginal opening is considerably anterior to this 
and thus has the appearance of being anterior to the pygidium. No pores or ducts of any sort are apparent either dorsally or ventrally.

In the very late second stage the derm becomes heavily chitinized and suffused with a black pigment. Apparently the derm dehisces around the posterior margin of the pygidium to permit the escape of the larvae. At an earlier period (Fig. 22F) the derm is membranous except for the pygidium, which is similar in form to the usual Diaspine type but entirely without lobes or plates (Fig. 22B), pointed and with the tip slightly emarginate. Anal ring borne about the center of the dorsal side of the pygidium. On both dorsal and ventral sides there are a number of small points which may be either pores or the points of insertion of small spines.

First stage. Derm heavily chitinized at the end of this period. Early first stage resembling that of other Diaspinae, but without lobes at the posterior end of the body (Fig. 22C). Antennae (Fig. 22E) sixsegmented, last segment not annulate.

\section{Protodiaspis edentata n. sp.}

Fig. 23.

Type host and locality. From Acacia greggii, near Vail, Ariz.

Habit. In all respects resembling the preceding. Male not observed.

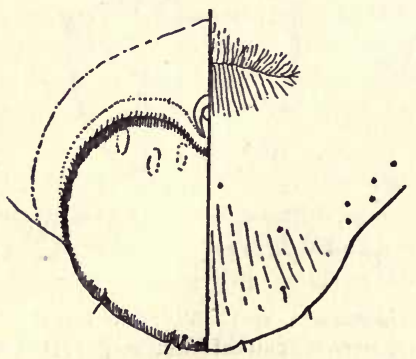

Fig. 23.-Protodiaspis edentata n. sp.: pygidium of adult female.

Morphological characteristics. Adult female with the pygidium quite smoothly rounded, bearing four small spines along its margin. On the dorsal side the anterior portion appears to be somewhat elevated above the remainder and separated from the remainder by a curving line. Anterior to this line the derm is rather weakly chitinized. On the ventral side the pygidium appears not to be sharply separated from the abdomen. 
In all the available individuals of the second stage the derm had become heavily chitinized, rendering them difficult to study. As far as may be ascertained the pygidium in this stage differs but little from that of the adult.

First stage as in P. tridentata.

Notes: It is this species that most closely resembles $P$. anomala Green. Were it not for its discovery $P$. tridentata might well have been made the type of a new genus.

\section{Genus DIASPIS Costa.}

\section{"Diaspis" arizonica Ckll.}

Fig. 24.

Type host and locality. From Prosopis velutina, several miles west of Phoenix, Ariz.

Material examined. From type host at Tucson, Ariz.

Scale. Scale of the female white, flattish, with the exuviae subcentral. Ventral scale quite thick. Scale of the male white, slightly elongate, with the exuvium toward one end. Both male and female scales are found in cracks in the bark.

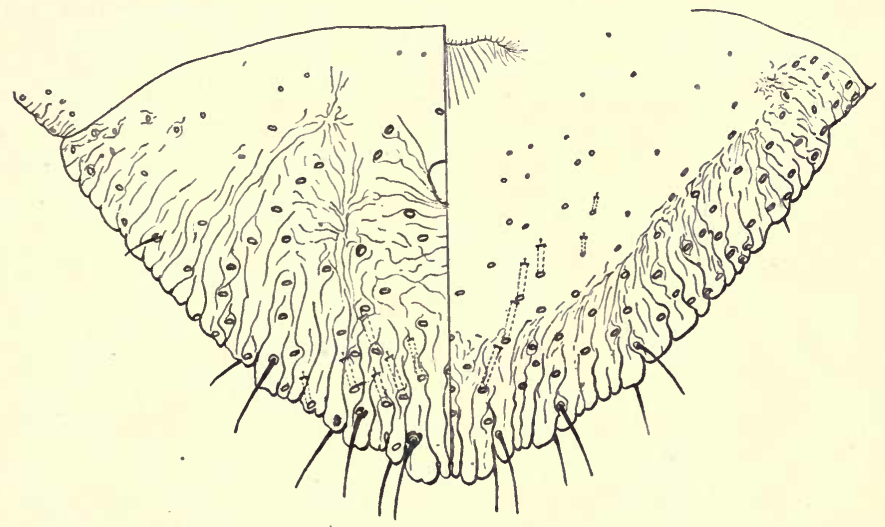

Fig. 24.-_Diaspis" arizonica Ck11.: pygidium.

Adult female with the anterior portion of the body quite heavily chitinized, the abdomen, except for the pygidium, membranous. Pygidium heavily chitinized, its surface presenting a wrinkled appearance. There are no plates. Three pairs of lobes present, these scarcely distinguish- 
able because of the crenulation of the margin of the pygidium, but their position marked by the spines arising from their bases. Anal opening somewhat nearer the anterior margin than the posterior. Tubular ducts abundant, short and quite slender, their orifices arranged in no definite manner. On the ventral side the wrinkling of the surface is confined to an area near the margin, this area bearing many tubular ducts. No circumgenital pores. Vaginal opening quite small, close to the anterior margin of the pygidium. Spines arising from the bases of the lobes quite long and slender.

Notes: Cockerell has described this species as a Diaspis but it certainly does not belong to this genus. In fact, it does not belong in the group of genera of which Diaspis is typical, being rather a member of the Aspidiotus group, the ducts being entirely of the latter type. However, I can not assign it to any named genus and I leave it in Diaspis for the present.

\section{Diaspis montana (Ckl1.).}

Fig. 25.

Type host and locality. From Quercus wrightii, Pinos Altos, N. Mex. According to the most recent authorities this is a synonym of $Q$. pungens.

Specimens examined. From Quercus emoryi, between Benson and Dragoon, Ariz.

Scale. Of the type common to the genus.

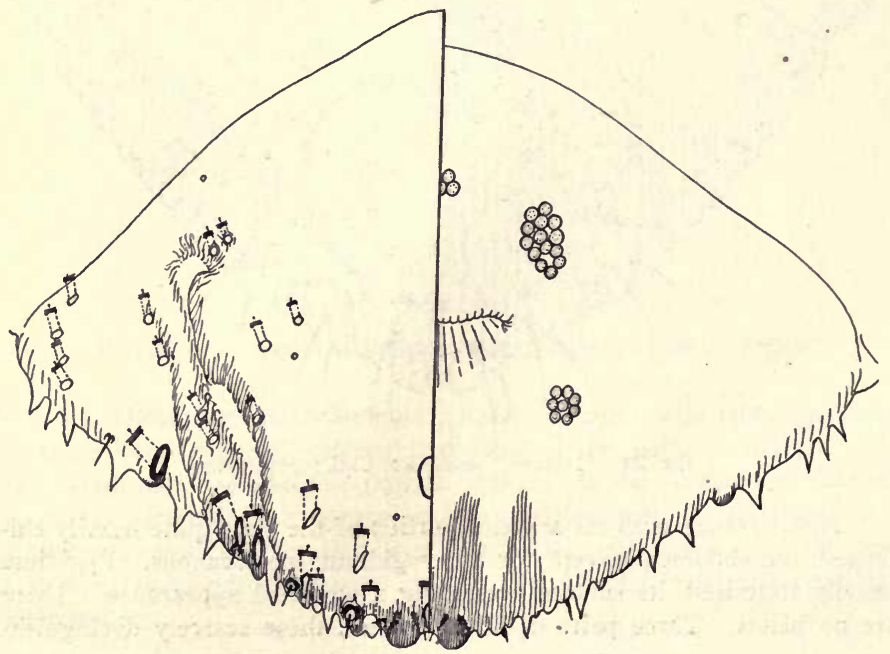

-Fig. 25.-Diaspis montana Ckll.: pygidium. 
Adult female. Derm membranous throughout except for the pygidium. Abdominal segments projecting somewhat at the margins and bearing numerous marginal gland spines and short tubular ducts. Dorsum of the abdomen destitute of submedian groups of ducts. Median lobes small, wide apart, rounded, projecting but little. Second pair of lobes very small, divided into two lobules, of which the inner is the larger. Third pair of lobes nearly or quite obsolete. Between the first and second lobes is a low gland prominence; between the second and third pair a gland spine followed by two low gland prominences; beyond the position of the third pair, a gland spine, a gland prominence and a series of six or more single gland spines. The marginal tubular ducts are considerably larger than those of the dorsum and their pores are surrounded by chitinous rims. Dorsal ducts few; their arrangement may best be gathered from the figure.

Notes: I would call attention to the close resemblance of this species in all essential characters to Epidiaspis pyricola (Del G.). I shall discuss the validity of the genus Epidiaspis in another paper.

\section{Diaspis toumeyi Ckll.}

Fig. 26.

Type host and locality. From Holacantha emoryi, near Maricopa, Ariz.

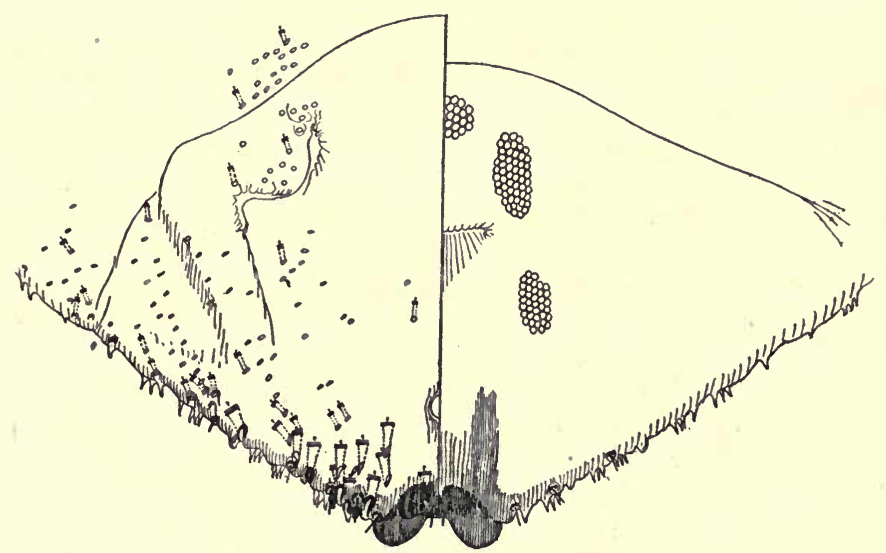

Fig. 26.-Diaspis toumeyi Ckll.: pygidium of specimen from Holacantha. 
Material examined. From Holacantha emoryi, near the Hassayampa River, west of Phoenix, and from Koeberlinia spinosa, between Bowie and San Simon, Ariz.

Scale. Of the type common to the genus.

Female. Derm membranous throughout except for the pygidium. Abdominal segments projecting but little at the margins and without marginal gland spines but with many small tubular ducts. Each abdominal segment dorsally with a submedian group of ducts on each side. Median lobes large, their mesal margins diverging rapidly, their tips rounded, sometimes slightly crenulate. Second and third pairs of lobes extremely small. Between the first and second pair is a single low gland prominence; between the second and third another. Beyond the third pair are many small gland spines arranged in clusters of three to five spines. Marginal ducts somewhat larger than those of the dorsum, their pores surrounded by a narrow chitinous rim. Dorsal ducts extremely numerous. Their arrangement may best be gathered from the figure. Five groups of circumgenital pores present, each group with many, pores.

Notes: In the specimens from Koeberlinia the second and third pairs of lobes are noticeably larger than in those from Holacantha, but there appear to be no other differences.

\section{Genus PSEUDODIASPIS Ckil.}

This genus appears never to have been definitely described, its author having merely stated that: "Pseudodiaspis will, however, no doubt eventually be regarded as a distinct genus, on account of the mytiliform male scale and other characters."

Through the kindness of Professor Cockerell I have been enabled to see a slide of $P$. larreae Ckll., the type of the genus. Unfortunately this slide is not in such condition as to permit the redescription of the species or even any very definite conclusions as to its character. The species does appear, however, to be of the Diaspis type rather than of the Aspidiotus type, the tubular ducts at the margin being of the character found in the former genus.

I am here utilizing this generic name to designate a group of species belonging to the Diaspis series, but agreeing in the absence of circumgenital pores and in having the scale of the male somewhat elongate, in texture resembling that of the female, with the exuviae near one end. That these species are congeneric with $P$. larreae or even with each other is perhaps questionable, but this seems to be the only genus available for them at present. One of them has been referred to Targionia, a genus that, if I may judge from the species available to me for study and from the literature, is purely artificial and of a most heterogeneous character, 
but the type of which is supposed to be related to Aspidiotus. The type, however, needs to be much more thoroughly elucidated before the validity of the genus is at all established.

\section{Pseudodiaspis atriplicis n. sp.}

Fig. 27.

Type host and locality. From Atriplex sp., along the river at the foot of the butte at Tempe, Ariz. Also from Atriplex sp., near Barstow and near Lone Pine, Cal.

Scale. Scale of the female circular, quite convex, white, with the exuviae central. First exuvium naked, silvery in color; second exuvium covered by secretion. Ventral scale very thin. Scale of the male resembling the female in texture but more elongate and with the exuvium at one end; exuvium naked, silvery in color as in the female.

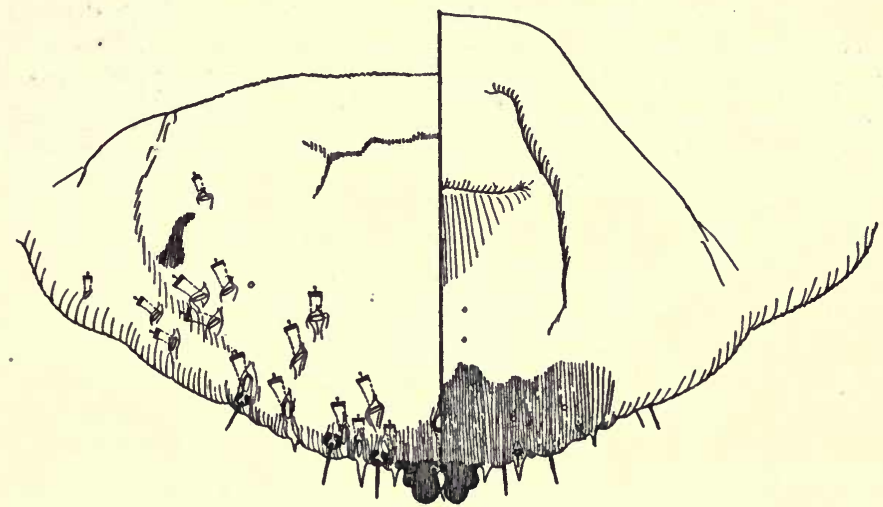

Fig. 27.-Pseudodiaspis atriplicis n. sp.: pygidium.

Female. Length (flattened on slide) $.8 \mathrm{~mm}$. General form broadly oval, with the posterior end slightly pointed. Cephalothorax somewhat chitinized. Pygidium with the median lobes alone present, these quite large, prominent, their mesal margins close together and parallel, their lateral margins deeply once-notched. At the mesal, basal angle of each lobe there is a stout spine. A similar spine marks the position of the obsolete second and third lobes and there is another spine farther out along the margin. All of these spines, except that at the base of the median lobes, have their sockets surrounded by a rather large, chitinized 
thickening. Between the median lobes and the position of the second pair is a single gland spine or prominence and just beyond the second lobe is another such prominence. Dorsal tubular ducts of practically the same size as those at the margin, few. The distribution of the ducts may best be determined from the figure. Anal opening very small, close to the posterior margin. On the ventral side the spines are all extremely small. Vaginal orifice situated in a depression as indicated by the figure.

Notes: I am inclined to regard this species as most closely related to the species which has stood as Targionia parkinsoniae (Ckll.) and which I am redescribing below.

\section{Pseudodiaspis condaliae n. sp.}

Figs. 28, 29.

Type host and locality. From Condalia spathulata, Tucson, Ariz.

Scale. Scale of female circular, rather high convex, with the exuviae central or sub-central ; first exuvium naked, second covered by secretion; ventral scale extremely thick at the margins, thinner in the center. Color of the scale light brown. Scale of male resembling that of female in color and texture, oblong, with the sides more or less parallel; with the exuvium near one end.

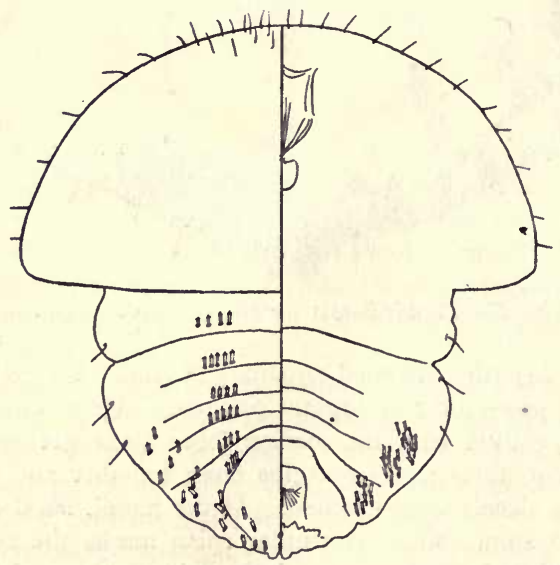

Fig. 28.-Pseudodiaspis condaliae n. sp.: outline of body, right half dorsal, left half ventral. 
Female. Length $.8 \mathrm{~mm}$. Cephalothorax (Fig. 28) heavily chitinized dorsally. Semicircular in form, much exceeding the abdomen in width. Abdomen membranous or but slightly chitinized; dorsum of each segment with a submedian group of small, tubular ducts, last two or three segments anterior to the pygidium with a few ducts near the lateral margin. On the ventral side the last three segments anterior to the pygidium bear many small ducts near the margins.

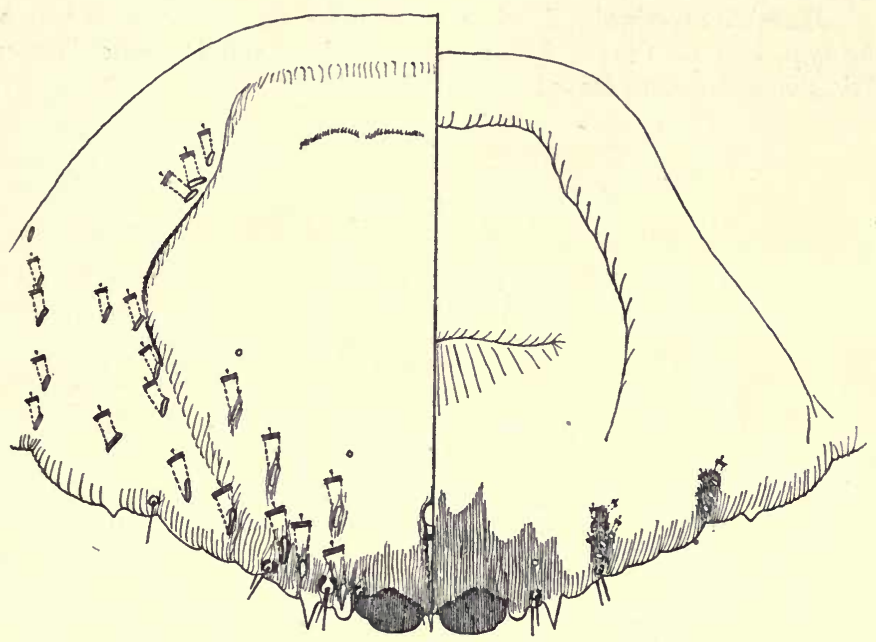

Fig. 29.-Pseudodiaspis condaliae n. sp.: pygidium.

Pygidium (Fig. 29) with the median lobes alone well developed, these broad and low, with the tips rounded, notched laterally. At each basal angle is a very small spine. A much larger spine marks the position of the obsolete second and third lobes. Between the first lobe and the position of the second is a single low gland prominence and just beyond the second lobe is a gland spine or plate. Anal opening small, quite near the posterior margin. Dorsal and marginal ducts of practically the same size, arranged as indicated in the figure. On the ventral side the spines are all quite small and there are four small, heavily chitinized areas extending in from the margin and bearing several small, tubular ducts. Vaginal orifice set in a depressed area.

Notes: The peculiar form of the female is alone sufficient to separate this species from the others here referred to this genus. 


\section{Pseudodiaspis parkinsoniae (Ckll.).}

Fig. 30.

1899. Xerophilaspis parkinsoniae Ck1l., Ariz. Exper. Station, Bull., $32: 282$.

1900. Xerophilaspis parkinsoniae Ck11.; Ckll., Can. Ent., 32:131.

1903. Targionia parkinsoniae (Ckll.); Fernald, Catalogue Coccidae, p. 298.

Type host and locality. From Cercidium (=Parkinsonia) torreyana, Phoenix, Ariz.

Material examined. Specimens from the type material and from the type host at Tempe, Ariz.; from Acacia paucispina near Tucson, Ariz.; from a narrow-leaved Yucca near Vail, Ariz.

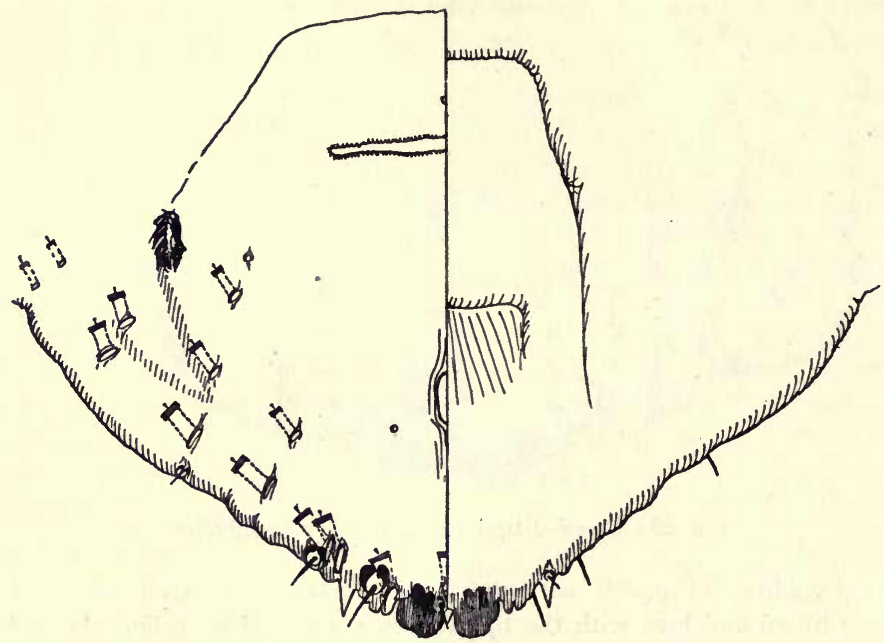

Fig. 30.-Pseudodiaspis parkinsoniae (Ck11.): pygidium.

Scale. Scale of the female circular, rather flat, with the exuviae subcentral. Color white. First exuvium naked, second exuvium covered with secretion. Ventral scale very thin. In specimens from Cercidium the second exuvium is deep black and heavily chitinized, in those from the other hosts it is of a lighter color. Scale of the male resembling that of the female in texture, oval, slightly elongate, with the exuvium near one end. 
Female. Adult female oval in form, the anterior end rounded, the pygidium slightly pointed; cephalothorax more or less heavily chitinized, not wider than the abdomen at its base. Pygidium with the median lobes well developed, rather square, with a notch on the lateral margin. Second pair of lobes present but very small, bilobed. Third pair of lobes obsolete. Between the first and second lobes is a low gland prominence and between the second and the position of the third a prominent plate or gland spine. A small spine is situated at the inner basal angle of each median lobe. A rather large spine marks the position of both the second and third lobes, the thickenings about the sockets of these spines being quite conspicuous. Dorsal tubular ducts few, slightly smaller than the marginal ducts; their arrangement is indicated in the figure. Anal opening at some distance from the margin. On the ventral side the spines are extremely small. Vaginal orifice small, set in a depressed area.

Notes: The specimens from Yucca differ from the others in having the second exuvium brown instead of black and in a tendency toward a much lighter chitinization of the cephalothorax of the adult female. Otherwise they are in all respects like the typical form.

\section{Genus XEROPHILASPIS Ckll.}

As far as I am able to determine this genus has never actually been defined. I present the following characterization of it:

Diaspine Coccidae in which the adult female is entirely enclosed by the exuvium of the second stage; adult female without circumgenital pores, without plates and with the lobes reduced to slight prominences: immature female with three pairs of well defined lobes and with large tubular ducts of the type found in Diaspis and related genera.

Type of the genus $X$. prosopidis Ckll.

Notes: As the genus Aonidia is at present understood $X$. prosopidis might well be considered as belonging to that genus. However, there can be but little question that the genus Aonidia in reality includes forms of very diverse phylogeny and that the retention of the adult female within the derm of the preceding stage is a character that has developed independently in totally unrelated groups. In fact a classification based upon the second stage would in all probability come much closer to expressing the real relationships of these curious forms than does that now in use. I therefore retain the genus Xerophilaspis rather than add one more to an already heterogeneous assemblage.

The real nature of $X$. prosopidis appears not to have been understood, for the exuvium of the second stage seems to have been confused with the secretionary scale and the differences between this stage and the adult have not been noticed. 


\section{Xerophilaspis prosopidis Ckll.}

Fig. 31.

Type host and locality. From Prosopis, near Phoenix, Ariz.

Material examined. From Prosopis velutina, near Tucson, Ariz., and from undetermined host (probably Prosopis sp.), San Diego, Cal.

Scale. Scale of the female circular, composed almost entirely of the hardened, jet-black second exuvium. Covering this exuvium is a very thin, white secretionary scale which is so transparent that it is frequently practically invisible. First exuvium naked. Before the hardening of the second exuvium the white secretionary scale is plainly visible. It is perhaps this stage which Cockerell has described as the scale of the male, although he has himself stated that he had described the male of Aspidiotus candidulus as the male of $X$. prosopidis. I have not myself seen the male.

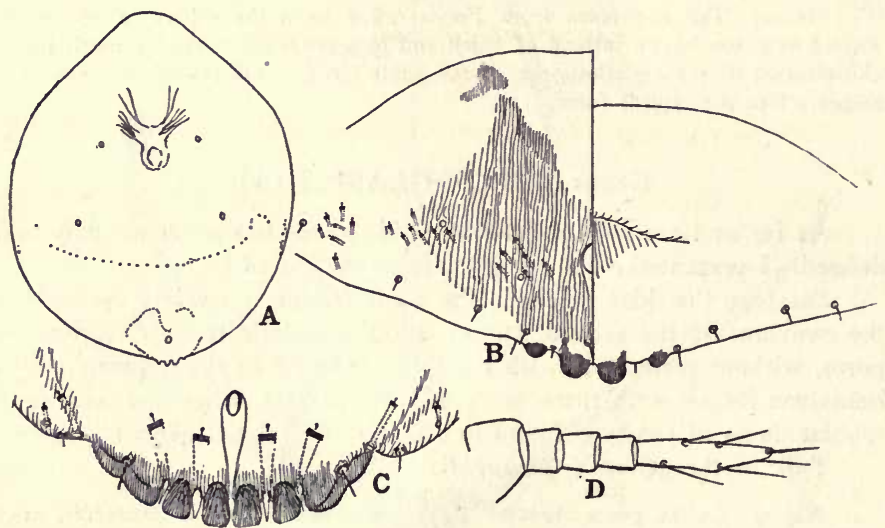

Fig. 31.-Xerophilaspis prosopodis Ckll.: A, adult female; B, pygidium of adult female; C, margin of pygidium of early second stage; D, antenna of first stage.

Female. Adult female (Fig. 31A) more or less circular in form, with the anterior end produced into a rounded projection; derm of the cephalothorax (which comprises far more than half of the body) heavily chitinized, especially in the anterior part. Pygidium (Fig. 31B) with two pairs of small lobes and with several submarginal spines, entirely without plates. Tubular ducts extremely small, arranged in a narrow, transverse belt at some distance from the margin and on a line passing 
through the anal opening. Circumgenital pores entirely lacking. In the early second stage female the derm is membranous, except for the pygidium. Pygidium (Fig. 31C) with two pairs of prominent, spatulate lobes and outside of these a third pair of lobe-like projections with the mesal margin perpendicular and the lateral margin sloping and slightly crenulate. Between the first and second, and second and third pairs is a small gland prominence at the base of which a large, tubular duct opens. In the late second stage the derm of the dorsum becomes very heavily chitinized and deeply pigmented (that of the venter remaining thin) and the characters of the pygidium are entirely obscured.

The first stage larva is of the ordinary Diaspine type; with one pair of small lobes; with the antennae (Fig. 31D) five-segmented, the last segment somewhat elongated but not annulate.

\section{Genus LEUCASPIS Targ.}

\section{"Leucaspis" cupressi Coleman.}

Fig. 32.

Type host and locality. From Cupressus goveniana, Lake County, Cal.

Material examined. The type slides and specimens from Juniperus pachyphloea, near Datil, N. Mex., and Libocedrus decurrens, near Yosemite National Park, Cal.

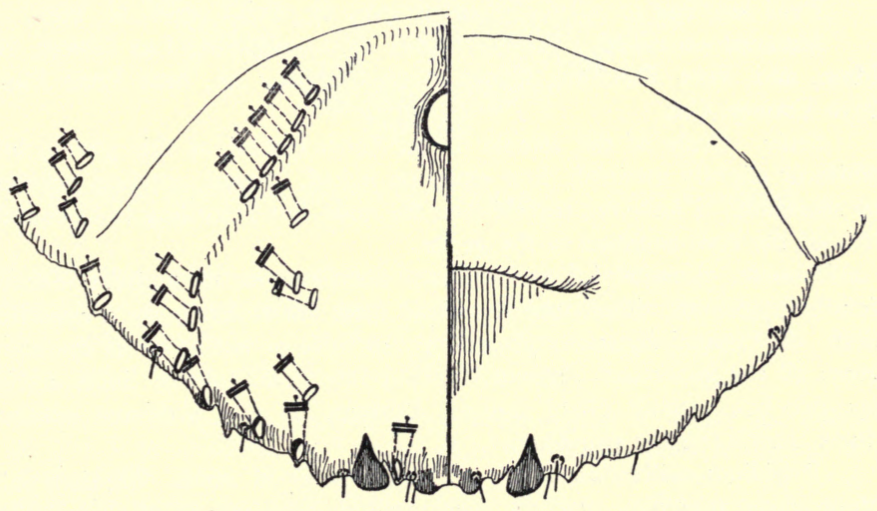

Fig. 32.- "Leucaspis" cupressi Coleman: pygidium. 
Scale. Scale of the female white, elongate, with the exuviae at one end, the first exuvium bare, the second covered with secretion. The second exuvium does not to the slightest extent enclose the adult female.

Female. Length $.8 \mathrm{~mm}$., broadly oval, the posterior end widest. Derm membranous throughout. Pygidium with the first pair of lobes extremely small, consisting of mere prominences; second pair much larger, projecting but little from the margin but with their chitinized bases prolonged somewhat into the pygidium. No plates, but the margin with a few small prominences. Ducts short and broad, arranged as indicated in the figure. Anal opening near the anterior end of the pygidium. Circumgenital pores lacking. The second stage resembles the adult in all respects.

Notes: This species is certainly not a Leucaspis, but as its generic position is quite uncertain I leave it for the present in that genus. The figure of the pygidium given by Coleman is quite erroneous in indicating the presence of large groups of pores on the dorsum.

\section{Genus LEPIDOSAPHES Shimer.}

\section{Lepidosaphes concolor (Ckll.).}

Fig. 33 .

1893. Mytilaspis albus var. concolor Ckll., Psyche, 6:572.

1903. Lepidosaphes concolor (Ck11.), Fernald, Catalogue Coccidae, p. 307.

1903. Anoidomytilus concolor (Ckll.); Leonardi, Annali di Agr., $5: 120$.

Type host and locality. From Atriplex sp., Las Cruces, N. Mex.

Material examined. From Atriplex canescens, near Las Cruces, N. Mex., and Fort Stockton, Texas; from Atriplex sp., near Lone Pine, Inyo County, Cal.

Scale. Scale of the female of the form typical of this genus, but white or slightly greenish, first exuvium naked, second exuvium covered by secretion. I have not myself seen the male, but according to Cockerell it is of the type common to the genus.

Female. Length $1.2 \mathrm{~mm}$. Derm membranous throughout, except for the pygidium; thorax not separated from the abdomen by a constriction. Abdominal segments projecting but little or not at all at the margins; all the abdominal segments with a few small tubular ducts at the margins but without gland spines. Dorsum of the abdomen without ducts anterior to the pygidium.

Pygidium with two pairs of well developed lobes. Median pair quite close together, straight, their mesal margins parallel; with a notch on both mesal and lateral margin at the tip. Second pair 
much less prominent than the first, bilobed and with the inner lobule notched at the tip. Mesal pair with a spine near the inner basal angle; second pair with a spine at the base of the inner lobule. Margin of the pygidium more or less heavily chitinized between the two pairs of lobes. Between the first and second pairs is a single large plate or gland spine; between the second and the position of the third is another such plate and beyond the position of the third pair of lobes are two more, wide apart. Marginal tubular ducts much larger than those of the dorsum

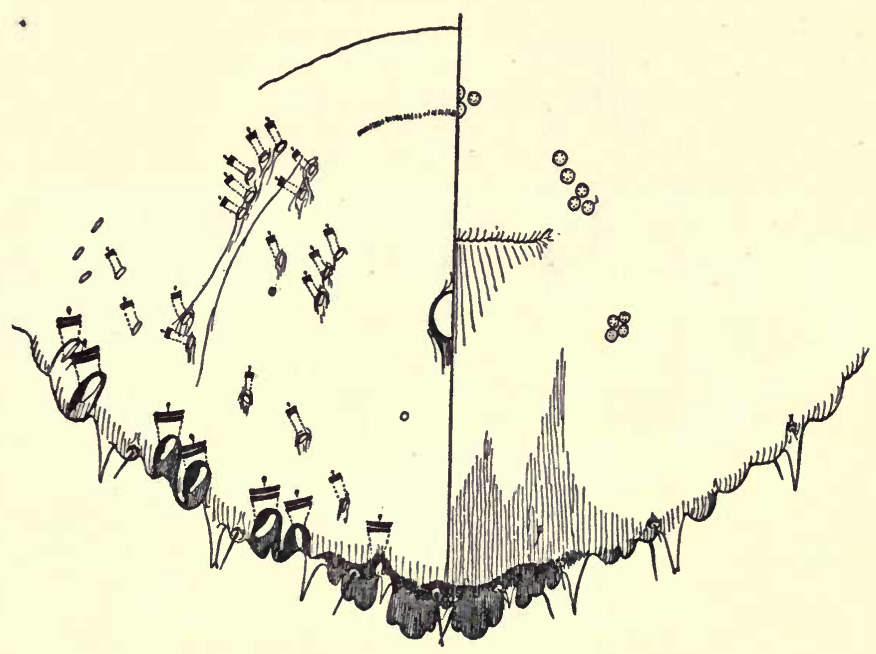

Fig. 33.-Lepidosaphes concolor Ckll.: pygidium of topotype specimen.

and with their pores surrounded by conspicuous, chitinized rims. The arrangement of these ducts may best be shown by the figure. On the ventral side the spines are very small. Circumgenital pores in five groups, the number of pores in each group small, four to eight.

Notes: The description of the genus Aonidomytilus, of which this species is the type, is not available and I do not know by what the genus is supposed to be distinguished. Aside from the color of the scale I see no character which may separate this species generically from $L$. ulmi. In fact, a direct comparison of the two species shows that they are morphologically very similar. In my opinion the genus Aonidomytilus can not be maintained. 


\section{Lepidosaphes ceanothi n. sp.}

Fig. 34.

1909. Mytilaspis concolor Ckll.; Essig, Pomona Col. Jn. Ent., 1:57. (Misidentification.)

Type host and locality. From Ceanothus jepsoni, Mount Tamalpais, Marin County, Cal. Also from Ceanothus integerrimus, Lake County, and Ceanothus sp., Redding, Cal.

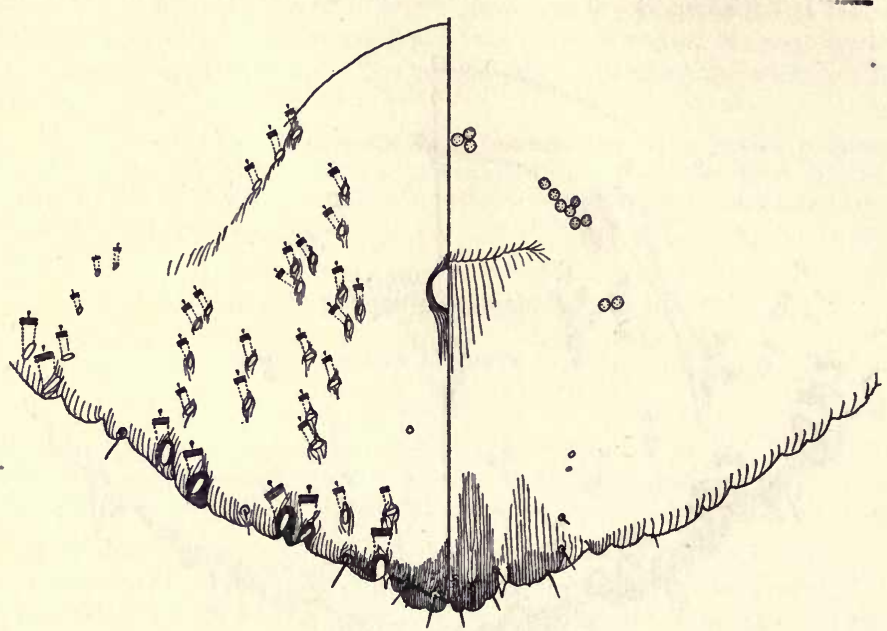

Fig. 34.-Lepidosaphes ceanothi n. sp.: pygidium.

Scale. Scale of the female white, similar to that of $L$. concolor. Scale of the male of the type common to the genus, but white.

Female. Length $1.3 \mathrm{~mm}$. Derm membranous throughout, except for the pygidium; thorax not separated from the abdomen by a constriction. Margins of the abdominal segments projecting little or not at all, with no gland spines but with numerous small ducts.

Pygidium with the median lobes alone well developed and with these sometimes very low and inconspicuous. Second pair of lobes present, but extremely low and sometimes apparently almost obsolete. A very small plate or gland spine between the first and second lobes, and occasionally one or two beyond the second lobes, but these always very small and usually lacking. Marginal tubular ducts considerably larger than those of the dorsum, their pores with a chitinized rim about 
the mouth. The arrangement of these ducts may best be gathered from the figure. Anal opening slightly nearer the anterior margin than the posterior. Circumgenital pores in five groups, the number of pores in each group very small (two to eight).

Notes: I am informed by Mr. Sasscer that this species stands in the National Collection as $L$. concolor Ckll., and it is apparently upon this determination that Essig's record of the occurrence of concolor on Ceanothus is based. Although the two species are certainly closely related they are obviously distinct, as a reference to the figures will at once show.

\section{Genus ASPIDIOTUS Bouché.}

\section{Aspidiotus candidulus Ckll.}

Fig. 35.

Type host and locality. From Prosopis velutina, Tucson, Ariz.

Material examined. From type host and locality.

Scale. Scale of the female flat, circular, rather thin, slightly yellowish; exuviae subcentral. Scale of the male somewhat oval, with the exuvium near one end.

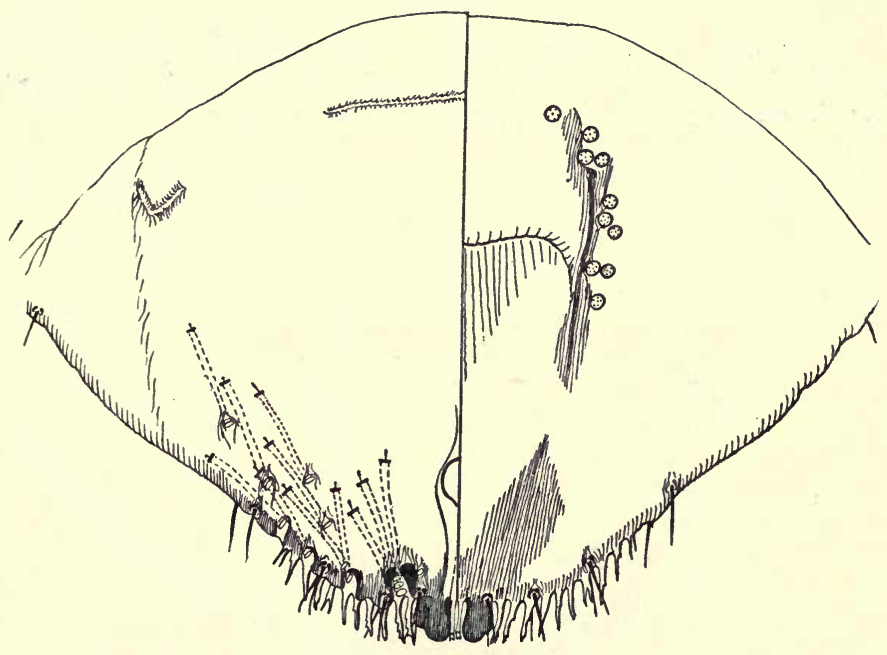

Fig. 35.-Aspidiotus candidulus Ckll.: pygidium. 
Female. Of the ordinary form; derm of cephalothorax but little chitinized. Pygidium with the median lobes alone well developed, the second and third pairs obsolete, their position indicated merely by the spines at their bases. Median lobes rather large, straight, parallel, with their outer margins notched near the tip. Between the median lobes is a pair of small plates and beyond the lobes is a continuous series of slender, toothed or slightly branched plates, ten or more in number. Spines rather long. First poriferous furrow (incision) with but four to five pores, second with but two to three; dorsal pores few ; ducts communicating with the pores moderately long and slender. The arrangement of the pores can best be described by the figure. Thickenings at the margins of the first poriferous furrow rather large, that of the mesal margin longest; thickenings of the second furrow inconspicuous. Anal opening only a short distance from the margin. Circumgenital pores in four groups, these more or less confluent and with but few pores, which are disposed along a thickening.

Notes: As Cockerell has indicated, this species is quite similar to A. lataniae, but the larger number of plates alone is sufficient to distinguish it.

\section{Aspidiotus covilleae n. sp.}

Fig. 36.

Type host and locality. From Covillea glutinosa, Mormon Flat, east of Phoenix, Ariz. Occurring beneath the loose bark on exposed roots in company with Chrysomphalus covilleae n. sp.

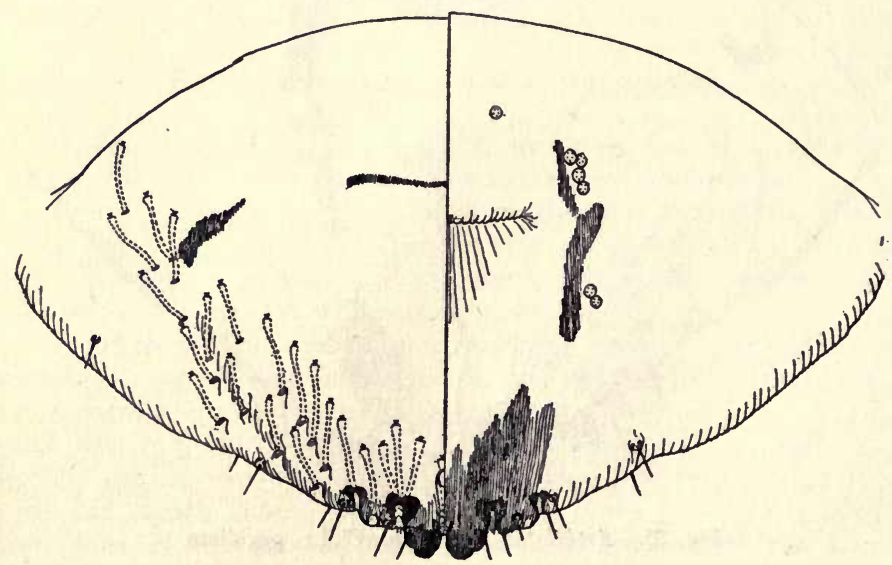

Fig. 36.-Aspidiotus covilleae n. sp.: pygidium. 
Scale. Scale of the female flat, circular, whitish, with the exuviae subcentral. Scale of the male not observed.

Female. Length $1 \mathrm{~mm}$. Of normal form; derm of cephalothorax but little chitinized.

Pygidium with the median lobes alone developed, the others entirely obsolete, their position indicated only by the spines at their bases and the position of the poriferous furrows (incisions). Median lobes quite prominent, parallel, with a notch in the lateral margin near the tip. There is a rather long spine arising from the outer basal angle and a similar spine marks the position of the second and third pairs of lobes. Plates entirely lacking. First poriferous furrow (incision) with but three to four pores, its margins bounded by rather conspicuous thickenings of about equal length. Second incision with a single pore and with smaller thickenings. Dorsal pores rather numerous. Ducts arising from the pores moderately long and slender. The arrangement of the pores is indicated by the figure. Circumgenital pores in four or five groups. Median group, when present, represented by but one or two pores; lateral groups with two to five pores, these disposed along a thickening.

Notes: Of the species known to me this most closely resembles $A$. ehrhorni Coleman, which occurs on certain conifers in California. The two are separable only by the fact that in ehrhorni small plates are present in the inter-lobular spaces and there are tubular ducts in the extreme lateral angles of the pygidium.

\section{Aspidiotus graminellus Ckll. ?}

Fig. 37.

1901. Aspidiotus graminelıs Ck11., Ann. Mag. Nat. Hist., (7), $7: 333$.

1903. Targionia graminella (Ck11.); Fernald, Catalogue Coccidae, p. 297.

Type host and locality. From grass, Las Vegas, N. Mex.

Material examined. From a perennial grass, probably Hilaria cenchroides, on the Jornada del Muerto, fifty-one miles north of Las Cruces, N. Mex.

Scale. Scale of the female white, circular, quite convex, with a rather thick ventral scale; exuviae covered with secretion, yellow when rubbed. Scale of the male resembling that of the female in color and texture, but elongate and with the exuvium at one end.

Female. Body of ordinary appearance, the cephalothorax more or less chitinized. Pygidium with two pairs of lobes. Median pair quite large and prominent, straight, their margins nearly parallel, their tips with several small teeth. Second pair very small and projecting but little from the margin, but nearly as broad as the first pair; inner margin straight, outer margin sloping, crenulate. Between the first and second 
lobes are two very small plates and just beyond the second lobe are two more, these slightly branched. Dorsal pores for the most part arranged in four rows which are set in more or less definite furrows as indicated

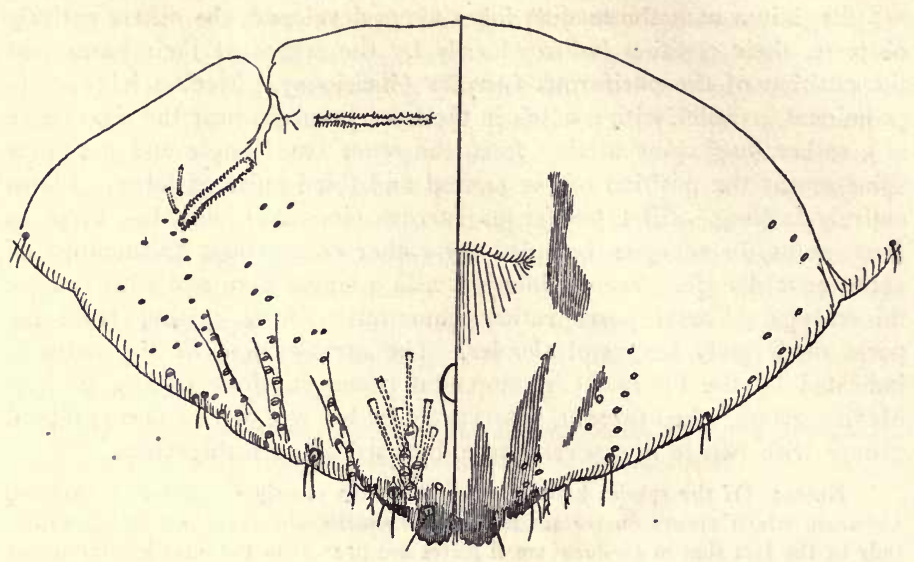

Fig. 37.-Aspidiotus graminellus Ckll. (?): pygidium.

in the figure. Ducts slender, moderately long. Ventral side with a few pores which possibly are the orifices of tubular ducts. Circumgenital pores lacking.

Notes: This is possibly not A. graminellus, as Cockerell speaks of three pairs of lobes and of thickenings at the bases of the lobes, but it is certainly rather close to that species, at least. It is not Targionia marlatti (Par.), a slide of which I have seen through the kindness of Professor G. A. Dean of the Kansas State Agricultural College.

As is the case with other species now referred to the genus Targionia it is questionable that this belongs to that genus and I am for the present leaving it in Aspidiotus.

\section{Genus CHRYSOMPHALUS Ashmead.}

Chrysomphalus covilleae n. sp.

Fig. 38.

Type host and locality. From Covillea glutinosa, Mormon Flat, east of Phoenix, Ariz. Found on the bark and in cracks on exposed roots. 
Scale. Scale of the female high convex, circular, with the exuviae subcentral and covered with secretion. The secretion covering the exuviae is white, that of the remainder of the scale brown. Ventral scale quite thick. Scale of the male resembling that of the female in color and texture, but oval in form and with the exuvium near one end.

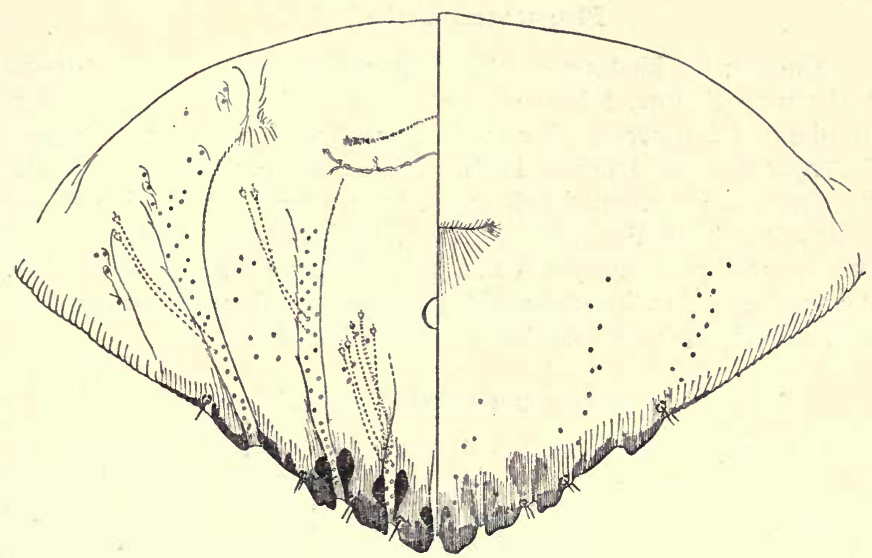

Fig. 38.-Chrysomphalus covilleae n. sp.: pygidium.

Female. Length $1 \mathrm{~mm}$; of ordinary form; derm membranous throughout, except for the pygidium, which is heavily chitinized. Margin of the pygidium with four pairs of lobes or lobe-like projections, these all more or less irregular in form and appearing somewhat like teeth. Each lobe with a small spine at its outer basal angle. Plates lacking. A short thickening extends into the pygidium from the inner basal angle of each median lobe and the margins of the first and second poriferous furrows show similar, but longer thickenings. Dorsal pores very abundant, their ducts long and filiform, arranged for the most part in three furrows as indicated by the figure. Ventral side of the pygidium with three rows of small pores which perhaps communicate with ducts. Circumgenital pores lacking.

Notes: A considerable number of species of this type have been described from Mexico and this may perhaps be one of them. However, few of these species have been figured and from the descriptions alone I cannot connect this with any of them. The bicolored scale of both male and female is quite striking. 


\section{SUPPLEMENT}

Since the preceding pages were sent to press a certain amount of information has come to hand, which it seems well should be included.

\section{Phenacoccus betheli Ckll.}

Through the kindness of Miss Eugenia McDaniel, of the Michigan Agricultural College, I have received some specimens of what is in all probability Phenacoccus dearnessi King. These specimens are from Crataegus sp., near Lansing, Mich. They agree in all respects with the description of $P$. dearnessi (which was taken from Crataegus in Canada) as far as the description goes. If this determination be correct, $P$. betheli Ckll. must fall as a synonym of $P$. dearnessi King, for the specimens from Michigan agree in all respects with the specimens from the type material of $P$. betheli which are recorded on a preceding page.

\section{Trionymus grindeliae Ferris.}

1918. Trionymus grindeliae Ferris, Cal. Species Mealy Bugs, p. 71, pl. 3, fig. 26.

From Professor Cockerell I have some specimens labeled "Ripersia confusella var. (light yellow), old mill, Las Vegas, N. Mex., Apr. 1902, W. P. C.," which are unmistakably Trionymus grindeliae Ferris, a species that has previously been recorded only from Pacific Grove, Cal. Whether $T$. grindeliae is the same as $R$. confusella remains to be seen.

\section{Aspidiotus graminellus Ckll.}

From Professor Cockerell I have also some specimens of what is beyond doubt $A$. graminellus, from Bouteloua sp. at Denver, Colo. (E. Bethel coll.). The specimens from New Mexico, which I have previously referred provisionally to this species, agree in all respects except for the absence of all trace of the third pair of lobes. This difference, however, is extremely slight and these specimens may quite definitely be referred to this species.

\section{Targionia covilleae (Ferris).}

Through the kindness of Mr. E. E. Green I have finally been enabled to examine specimens of Targionia nigra (Sign.), the type of the genus. With this the species described on a preceding page as Chrysomphalus covilleae $\mathrm{n}$. sp. appears to be strictly congeneric. It is, I believe, the only species thus far described from North America that may correctly be referred to this genus. 

DATE DUE

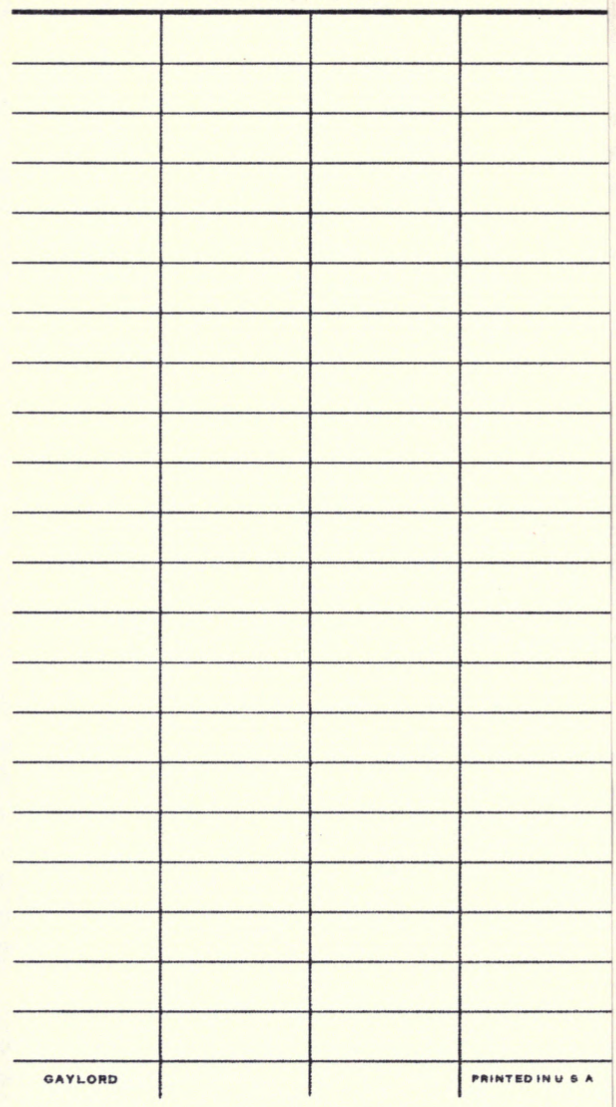




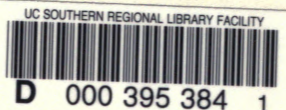


